OPEN ACCESS

Edited by:

Mohamed Abu-Farha, Dasman Diabetes Institute, Kuwait

Reviewed by:

Jeffery Sivert Tessem, Brigham Young University, United States Hadi Al-Hasani,

Heinrich Heine University of Düsseldorf, Germany

*Correspondence: Beatrice M. Filippi b.m.filippi@/eeds.ac.uk

${ }^{\dagger}$ These authors have contributed equally to this work

Specialty section: This article was submitted to Diabetes: Molecular Mechanisms, a section of the journal

Frontiers in Endocrinology

Received: 07 July 2020 Accepted: 05 October 2020 Published: 09 November 2020

Citation: Haigh JL, New LE and Filippi BM (2020) Mitochondrial Dynamics in

the Brain Are Associated With

Feeding, Glucose Homeostasis, and Whole-Body Metabolism.

Front. Endocrinol. 11:580879. doi: 10.3389/fendo.2020.580879

\section{Mitochondrial Dynamics in the Brain Are Associated With Feeding, Glucose Homeostasis, and Whole-Body Metabolism}

\author{
Jessica L. Haigh ${ }^{\dagger}$, Lauryn E. New ${ }^{\dagger}$ and Beatrice M. Filippi ${ }^{*}$ \\ Faculty of Biological Sciences, School of Biomedical Sciences, University of Leeds, Leeds, United Kingdom
}

The brain is responsible for maintaining whole-body energy homeostasis by changing energy input and availability. The hypothalamus and dorsal vagal complex (DVC) are the primary sites of metabolic control, able to sense both hormones and nutrients and adapt metabolism accordingly. The mitochondria respond to the level of nutrient availability by fusion or fission to maintain energy homeostasis; however, these processes can be disrupted by metabolic diseases including obesity and type II diabetes (T2D). Mitochondrial dynamics are crucial in the development and maintenance of obesity and $\mathrm{T} 2 \mathrm{D}$, playing a role in the control of glucose homeostasis and whole-body metabolism across neurons and glia in the hypothalamus and DVC.

Keywords: mitochondrial dynamics, brain, feeding, glucose-insulin, metabolism

\section{INTRODUCTION}

Mitochondria are essential for the control of energy metabolism and their dysfunction plays a key role in the pathophysiology of obesity and type II diabetes (T2D). They are dynamic organelles that change morphology in response to energy demand and supply via fission and fusion. Fission is mediated by the GTPase dynamin-related protein 1 (DRP1) and occurs when mitochondria are damaged or subjected to high levels of cellular stress $(1,2)$. DRP1 is recruited to the outer mitochondrial membrane (OMM) where it oligomerizes to form a ring structure to constrict the mitochondrion and fragment it $(3,4)$; this allows for a reduction in ATP content when energy supply exceeds demand. Fusion is also mediated by GTPases which include mitofusin 1 (MFN1), mitofusin 2 (MFN2), and optic atrophy protein 1 (OPA1) (5-7). MFN1 and MFN2 are anchored to the OMM and mediate fusion there, while OPA1 is involved in inner mitochondrial membrane (IMM) fusion. Mitochondrial fusion serves to repair damaged mitochondria by fusing them with a functional one and also increases ATP production to meet metabolic demand (2). Mice lacking $\operatorname{Drp1}, M f n 1, M f n 2$, or Opa1 are embryonic lethal $(5,8-10)$, demonstrating their essential role in development and highlighting their potential to influence metabolism if expression levels change.

Circuits within the central nervous system (CNS) control whole-body energy metabolism. The hypothalamus and the dorsal vagal complex (DVC) have been highlighted as crucial regulatory centers of metabolism, and dysfunction of mitochondria in these regions has been implicated in metabolic disorders. The arcuate nucleus (ARC) of the hypothalamus and area postrema (AP) of the DVC are sites with increased blood-brain barrier (BBB) permeability allowing for detection of 
circulating nutrients, such as glucose and free fatty acids, and hormones that have restricted entry to other brain regions (11). The ability to sense humoral signals means these regions can respond to environmental cues and adapt metabolism accordingly. Within the $\mathrm{ARC}$, anorexigenic proopiomelanocortin (POMC)- and orexigenic agouti-related peptide (AgRP)-expressing neurons regulate energy expenditure, glucose homeostasis, and food intake in an antagonistic fashion. Glial cells are also involved in body weight homeostasis, glucose metabolism, and obesity, with roles for both microglia and astrocytes (12-16).

In this review, we discuss the contribution of mitochondrial dynamics and dysfunction in the brain to the central control of metabolism and glucose homeostasis and their role in the metabolic disorders obesity and T2D.

\section{BRAIN INFLAMMATION, ER STRESS AND MITOCHONDRIA IN OBESITY AND T2D}

The body must respond and adapt to changing levels of energy input and availability by altering metabolism. This occurs at the molecular and transcriptional levels to give systems level changes and alterations in behavior. Mitochondria respond to nutrient availability by fusion or fission to maintain homeostasis; however, these processes can be disrupted by metabolic disease. Obesity and its many co-morbidities are associated with chronic inflammation, ER stress, and disrupted mitochondrial dynamics in several tissues [reviewed in (17-20)].

Obesity triggers a chronic low-grade inflammatory response in multiple organs which presents a complex challenge for deciphering the disease mechanisms. The mitochondria produce adenosine triphosphate (ATP) using nutrients and oxygen in a series of stepwise reactions that occur at the inner mitochondrial membrane (IMM). This process is the main source of reactive oxygen species (ROS), important for cell functions and acting as a signaling molecule; however, high ROS levels are associated with cell damage. Excessive nutrient intake overloads the mitochondria with glucose and fatty acids leading to an increase in ROS production and associated oxidative stress in the skeletal muscle $(21,22)$. Obesity leads to reduced $\beta$-oxidation, a process where fatty acids are broken down to generate acetyl-CoA for use in the citric acid cycle (23). The reduction in $\beta$-oxidation impairs cellular functions via increased triacylglycerol synthesis and ectopic deposition of lipids; it also causes oxidative stress via an increase in lipid peroxidation byproducts, increased nitric oxide synthase, and excess ROS (24). High-fat diet (HFD) in rats reduced the activity of antioxidant enzymes superoxide dismutase, glutathione peroxidase, and catalase in the brain, thus further increasing ROS levels (25). When ROS production is exacerbated, for example by increased lipid availability, mitochondrial dysfunction is induced, and ATP production is decreased (26). ROS activate several transcription factors including $\mathrm{NF}-\kappa \mathrm{B}$, which is the primary mediator of the inflammatory response. HFD in mice increased NF- $\kappa$ B activity in multiple tissues (27) and activated inflammatory pathways in the hypothalamus leading to insulin resistance $(28,29)$. Levels of macrophages and $\mathrm{T}$ cells are increased in the skeletal muscle of obese patients with insulin resistance or $\mathrm{T} 2 \mathrm{D}(30,31)$, and short-term overfeeding in healthy subjects increased macrophage markers in the skeletal muscle and impaired insulin signaling (32), illustrating that inflammatory processes are also triggered by metabolic disorder in humans. Another family of inflammatory molecules c-Jun N-terminal kinases (JNKs) are activated in obesity; when JNK1 KO mice were fed HFD they gained less weight, had smaller adipocytes, and improved insulin sensitivity compared to wildtypes (33). Immune responses throughout the body and metabolic regulation are highly integrated, and the proper function of each is dependent on the other.

The endoplasmic reticulum (ER), a complex protein folding and trafficking organelle, interacts with the mitochondria and is another source of ROS. The ER can transduce signals from lipid metabolites and cytokines to stress kinases and plays an important role in insulin resistance (34). ER-mediated ROS production is increased in insulin resistant non-diabetic obese patients and T2D patients $(35,36)$. During cellular stress, as seen in T2D patients, ER function is disrupted by the unfolded protein response (UPR); this leads to calcium leakage from the ER which interferes with electron transfer in the electron transport chain and ultimately induces mitochondrial ROS production (37). There are three major transducers of the UPR: protein kinase RNA (PKR)-like ER kinase (PERK), inositol-requiring enzyme 1 (IRE1), and activating transcription factor 6 (ATF6). Downstream signaling leads to transcription of UPR target genes including upregulation of molecular chaperones and folding catalysts to increase the folding capacity of the ER, conveying a protective effect for cell survival. The UPR is an acute response to re-establish cellular homeostasis following stress; however, if sustained chronically it can lead to disease including obesity, T2D, and neurodegenerative disorders to name a few (38). ER stress is triggered in obese subjects by the release non-esterified fatty acids from visceral adipose tissue which causes the increased expression of cytokines and activation of PERK (39). Phosphorylated PERK modulates insulin responsiveness in adipose tissue through generation of phosphatidic acid, an inhibitor of insulin action (40). Furthermore, PERK-dependent mechanisms can induce positive ER stress feedback that perpetuates the process, contributing to the development of insulin resistance (39). A recent in vitro study found that ER stress and the UPR cause insulin resistance by depleting the cell surface population of the insulin receptor, impairing the transport of newly synthesized proreceptors (41). This effect of ER stress on trafficking insulin receptors to the surface may account for the decrease in insulin receptors seen in T2D patients. ER stress was detected in the hypothalamus of leptin-deficient neonate mice $(o b / o b)$ before the development of obesity at postnatal day 10 (P10) (42). Administration of the ER stress-relieving compound TUDCA during a critical developmental window for the hypothalamus (P4-P16) provided beneficial effects on body weight, food intake, adiposity, and glucose homeostasis that persisted into adulthood (42). ER stress throughout life therefore has a strong impact on 
metabolic regulation, including the hypothalamic circuits involved in feeding behavior.

Along with an upregulation in mitochondrial ROS production, dysfunction in mitochondrial dynamics is also associated with metabolic disease. A decrease in number of mitochondria and reduction in bioenergetic capacity have been measured in T2D patients (43). Reduced expression of the mitochondrial fusion mediator MFN2 was seen in skeletal muscle of obese Zucker rats and non-obese T2D patients (44, $45)$. Both genetically obese and diet-induced obese mice were found to have smaller and shorter mitochondria in the skeletal muscle, while inhibition of fission improved systemic insulin sensitivity (46). Rats on HFD for 8 weeks presented with impaired mitochondrial respiration and insulin resistance in hepatocytes (47). Treatment of hepatocytes with high glucose caused the mitochondria to become smaller and shorter; when a dominant negative form of DRP1, Drp1-K38A (a point mutation at Lysine-38 to Alanine in the catalytic site) was expressed in the cells, mitochondrial fission was prevented following glucose administration (48). In the adipose tissue of morbidly obese patients, an inverse relationship was found between the regulation of inflammation and mitochondrial function (49), and adipocytes in obese and diabetic mouse models had decreased mitochondrial mass and function (50).

Clear roles for aberrant mitochondrial dynamics have therefore been shown in peripheral tissues during the development of insulin resistance and obesity. Oxidative stress and ER stress are associated processes that both result in inflammation and are linked to the development of insulin resistance in many tissues including liver, skeletal muscle, adipose tissue, and brain. Mitochondria are crucial in maintaining energy balance and are therefore key players in the pathophysiology of metabolic disorders in peripheral organs as well as in the central nervous system.

\section{ENERGY HOMEOSTASIS AND MITOCHONDRIAL DYNAMICS IN THE HYPOTHALAMUS}

The mediobasal hypothalamus $(\mathrm{MBH})$ is critical for the regulation of appetite, feeding behavior, and body weight. Specific populations of neurons within the ARC respond to circulating hormones including insulin, leptin, and ghrelin to maintain energy homeostasis (51). AgRP/NPY neurons release GABA and directly inhibit POMC neurons (52). The binding of insulin in the ARC causes hyperpolarization of AgRP neurons via $\mathrm{PI} 3 \mathrm{~K} / \mathrm{Akt}$ pathway and subsequent $\mathrm{ATP}$-sensitive $\mathrm{K}^{+}\left(\mathrm{K}_{\mathrm{ATP}}\right)$ channel activation, alleviating the inhibitory constraints on POMC neurons $(53,54)$. Insulin binding in the ARC causes a decrease in hepatic glucose production (HGP) via vagal efferent signaling to the liver (55) and promotes negative energy balance by reducing food intake (56). Leptin binding in the ARC activates POMC neurons and inhibits AgRP neurons to reduce feeding, increase energy expenditure, and decrease HGP (57-59). The central action of these hormones plays an important role in the control of whole-body metabolism through signaling to peripheral organs. Insulin and leptin resistance are hallmarks of obesity, occurring following overnutrition and before the onset of major weight gain (60), and both are associated with mitochondrial dysfunction in the brain (61).

In hunger-promoting AgRP/NPY neurons, fasting increases mitochondrial fission whereas feeding and overnutrition promote fusion via MFN1 and MFN2 (62) (Figure 1). In a mouse model of diet-induced obesity (DIO), silent AgRP/NPY neurons presented with mitochondria that were increased in size and more elongated than those in wildtypes (62), demonstrating a role for mitochondrial fusion in AgRP neuronal response to overnutrition. Interfering with mitochondrial fusion in AgRP neurons by deletion of $M f n 1$ or $M f n 2$ resulted in altered mitochondria size and density, as well as some physiological phenotypes (62). Mice lacking $M f n 1$ in AgRP neurons displayed no metabolic phenotypes on a regular chow diet; however, following HFD food intake and body weight were decreased in female mice, and AgRP neuronal firing rate was decreased in both males and females. $M f n 2$ deletion in AgRP neurons did not alter the number of mitochondria but led to a decrease in body weight of females fed regular chow. AgRP-Mfn $2^{-/-}$mice fed HFD gained less weight compared to wildtype mice. AgRP firing rate was decreased, and the number of mitochondria was increased due to failed fusion (62). Altogether these data indicate a critical role for mitochondrial fusion in AgRP neurons in the maintenance of metabolism and appropriate weight gain following overnutrition.

Mitochondrial remodeling enzymes are also implicated in anorexigenic POMC neuronal signaling. Following feeding, mitochondrial fusion occurs in POMC neurons; this is mediated by a reduction in activated DRP1 levels (63) (Figure 1). Deletion of $M f n 1$ and $M f n 2$ in POMC neurons leads to a strikingly different phenotype compared to AgRP/NPY-specific deletion of these key fusion proteins $(62,64,65)$. MFN1 and MFN2 have non-redundant and distinct roles; MFN1 is more efficient at mediating the process of mitochondrial fission than MFN2 (66), whereas MFN2 is also involved in the establishment of mitochondrial-endoplasmic reticulum (ER) contacts (67). These differences are exemplified by discordant alterations in POMC neuron function following specific KO of either $M f n 1$ (65) or Mfn2 (64).

In DIO mice downregulation of $M f n 2$ alters mitochondrial network dynamics, reduces mitochondria-ER contacts, and impairs intracellular $\mathrm{Ca}^{2+}$-handling $(64,68)$. Ablation of $M f n 1$ in POMC neurons in mice led to defective mitochondrial architecture remodeling following feeding (65). Mice also presented with reduced insulin secretion by pancreatic $\beta$-cells after glucose challenge; this was recovered following administration of a sympathetic antagonist, suggesting a neural basis for the mechanism. Loss of $M f n 1$ caused an increase in mitochondrial respiration and ROS production in fed, but not fasting, conditions compared to wildtype mice (65). Deletion of Opa1 in the same neuronal population caused reduced mitochondrial fusion; however, neuronal activation, insulin secretin and hypothalamic ROS production remained unchanged (65). Selective ablation of 


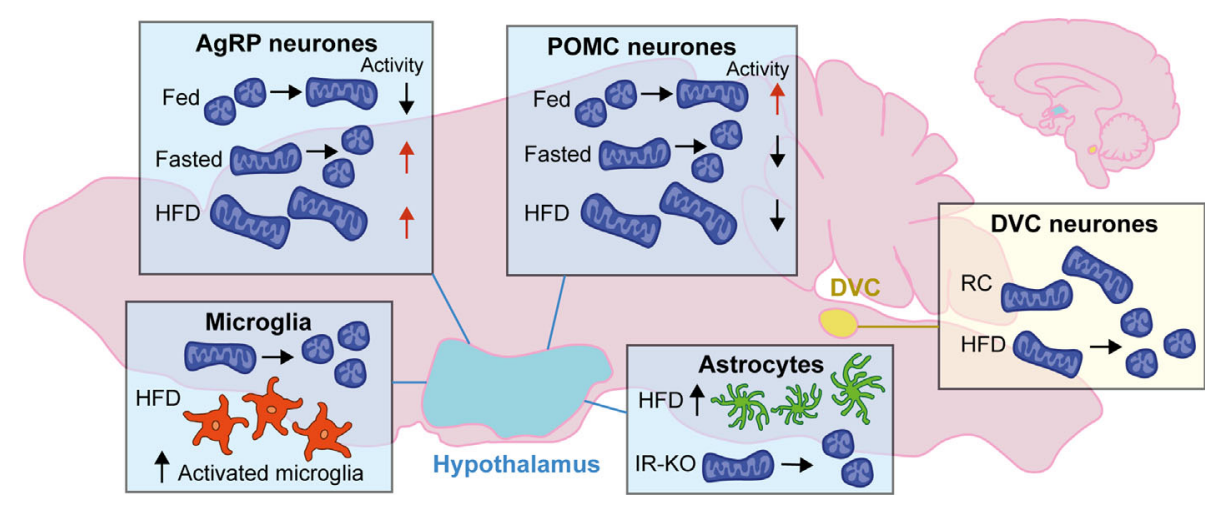

FIGURE 1 | Changes to mitochondrial dynamics in response to diet in the hypothalamus and DVC: Mitochondrial dynamics in the brain change depending on energy status. In the hypothalamus, neurons favor mitochondrial fusion following feeding and fission when fasted. The activity of AgRP and POMC neurons are antagonistic; following feeding AgRP neurons decrease activity while POMC neuron activity is increased while in the fasted state it is the opposite. Following high-fat diet (HFD) mitochondria favor fusion and become enlarged; AgRP neurons are highly active, and POMC neuronal activity is decreased. In microglia of the hypothalamus mitochondria favor fission with HFD, and there is an increase in the number of activated microglia in the ARC. There is also an increase in the number of astrocytes in the hypothalamus with HFD, and knockout of the insulin receptor (IR-KO) in astrocytes led to favoring mitochondrial fission. In the DVC, HFD leads to mitochondrial fission when compared to regular chow $(R C)$ fed rodents.

$M f n 2$ from POMC neurons in mice (POMCMfn2KO) caused leptin resistance, hyperphagia, and a reduction in energy expenditure and obesity (64). MFN2 is involved in tethering the ER to mitochondria (67), and deletion is known to cause ER stress $(64,69)$. Mitochondria-ER contacts were significantly reduced in POMCMfn2KO mice; ER stress markers were upregulated, and ROS levels were increased (64). Interestingly, antioxidant enzymes were increased in the hypothalamus of these mice, suggesting a potential compensatory mechanism to reduce excess ROS. When ER stress was relieved with the chemical chaperone 4-phenylbutyric acid (4-PBA) food intake and body weight were normalized in POMCMfn $2 \mathrm{KO}$ mice, while there were no changes in control mice (64). Together these data highlight the role of mitochondrial fusion and ER stress in POMC neurons as regulators of central metabolic signaling and responsiveness to circulating satiety factors both centrally and in peripheral tissues. In further agreement for the role of mitochondrial fusion in POMC neuron function, the fission mediator DRP1 was found to be phosphorylated (Ser616) and active in silent POMC neurons (63). Inducible deletion of Drp1 in POMC neurons led to increased neuronal activity, improved leptin sensitivity, and glucose metabolism, as well as increased hepatic glucose output (63). Mitochondria were increased in size, and ROS production was increased.

Anorexigenic POMC neurons are inhibited by increased mitochondrial fission leading to reduced energy expenditure and increased weight gain. Conversely, when fission is increased in orexigenic AgRP/NPY neurons it is beneficial in terms of weight gain, and increased caloric intake does not result in the same increase in body weight. HFD is associated with mitochondrial fusion in both POMC and AgRP neurons with opposing effects on neuronal activity; POMC neuronal activity decreases, while AgRP neuronal activity increases, leading to further increased food intake $(62,68)$ (Figure 1). Collectively, these data demonstrate the importance of mitochondrial dynamics in neuronal populations of the $\mathrm{MBH}$ and their role as essential regulators in the modulation of metabolism.

\section{MITOCHONDRIAL DYNAMICS AND WHOLE-BODY METABOLISM IN THE DVC}

More recently it was discovered that the DVC of the brainstem is involved in metabolic homeostasis and central response to insulin (70-72). The DVC consists of three regions: the dorsal motor nucleus (DMX), the nucleus tractus solitarius (NTS), and the AP. It is a site of integration, receiving signals from the peripheral organs and relaying them to the brain, while also relaying brain signals to the peripheral organs; this makes it a crucial region when studying neuronal control of physiological functions. Insulin in the DVC activates Erk1/2 rather than PI3K/ Akt signaling as it does in the $\mathrm{MBH}$ (70). Infusion of insulin in the DVC of rodents lowered hepatic glucose production, and activation of $\mathrm{K}_{\mathrm{ATP}}$ channels was required for insulin-Erk1/2 action (70).

HFD feeding in rodents induces insulin resistance (60), both in peripheral organs and in the brain $(70,73)$. After just three days of HFD infusion of insulin into the DVC fails to activate Erk1/2, where this central insulin resistance occurs prior to substantial weight gain and is bypassed by activation of $\mathrm{K}_{\mathrm{ATP}}$ channels in the DVC by diazoxide (70). Furthermore, acute insulin infusion into the DVC decreased food intake in regular chow fed rats but failed to do so in HFD-fed rats (71). Upon overnutrition, mitochondria undergo Drp1-mediated fission in DVC neurons, thereby suggesting a role for mitochondrial dynamics in DVC insulin resistance (72) (Figure 1). Indeed, inhibition of DRP1 via infusion of MDIVI-1, which blocks DRP1 translocation from the cytosol to the mitochondria (74), in the 
DVC reversed the HFD-induced changes to mitochondrial dynamics and prevented the development of insulin resistance (72). DRP1 is regulated by post-transcriptional modifications including phosphorylation and SUMOylation (75); a decrease in phosphorylation of serine-637 increases DRP1 activity (76). When Drp1 activity was increased via delivery of a phosphodeficient mutant (Drp1-S637A) in the DVC of healthy regular chow fed rats, insulin resistance was induced (72). ER stress is necessary for Drp1-dependent mitochondrial fission to induce insulin resistance in the DVC. When the ER stress inhibitor 4PBA was delivered to the DVC of HFD-fed rats, the ability of insulin to lower glucose production was restored (72). Together these data demonstrate the importance of Drp1-mediated mitochondrial fission and ER stress in the DVC in the development of insulin resistance following overnutrition and highlight the potential therapeutic targets in the treatment of obesity and T2D.

Studies into the role of mitochondrial dysfunction in the brainstem and the effect on metabolism are still relatively novel. It is yet to be elucidated whether disruption of mitofusins or OPA1 in the DVC can alter feeding behavior and HGP. While there is a clear role for mitochondrial dysfunction in the development of insulin resistance in the DVC, it is unknown as to whether it also contributes to leptin resistance. More research is therefore required to define the role of mitochondria in the DVC in the development of obesity and T2D.

\section{ENERGY HOMEOSTASIS AND MITOCHONDRIAL DYNAMICS IN GLIAL CELLS}

Mitochondrial function is crucial to all cell types, and disruption in glial cells of the brain is associated with metabolic disorders (14). Astrocytes and microglia produce cytokines that drive inflammation and thus are mediators of the response to overnutrition and are involved in the development of obesity and T2D (77). Astrocytes and microglia may develop a reactive phenotype in response to injury or disease, also referred to as gliosis, which can be measured by changes in morphology and protein expression. Acute gliosis is protective and beneficial to neurons, but chronic activation can be detrimental. Increased gliosis has been measured in the hypothalamus of obese humans and in rodent models of obesity (77) (Figure 1).

Astrocytes regulate essential aspects of CNS function and brain energy metabolism (78). Their physical proximity to blood vessels and ability to transport nutrients mean they are directly affected by nutrient excess. Astrocytes exhibit a high rate of oxidative metabolism (79) and can switch between oxidative phosphorylation and glycolysis for their energy supply depending on local energy needs $(80,81)$. Inflammation alters mitochondrial dynamics in astrocytes where Drp1 is phosphorylated leading to increased fission, ROS production, and reduced respiratory capacity (82). Thus, the low-grade chronic inflammation associated with obesity is likely to mediate some of its effect via astrocytes.
Mice fed HFD for 10 days had an increased number of astrocytes in the ARC of the hypothalamus (83) (Figure 1). Inhibition of NF- $\kappa \mathrm{B}$ in astrocytes prevented acute HFD-induced astrocyte activation and reduced food intake (84). DREADDmediated activation of astrocytes in the DVC of mice reduced dark-phase feeding and reduced refeeding after overnight fasting (12). Furthermore, activation of DVC astrocytes induced signaling in the lateral parabrachial nucleus (12), another region involved in appetite regulation and glucose homeostasis (85-87). Conditional deletion of $M f n 2$ in astrocytes of mice led to a reduction in mitochondria-ER contact sites within astrocytes and associated disruption of calcium buffering; however, this study did not measure changes related to feeding (88). Targeted postnatal ablation of the insulin receptor in astrocytes of mouse hypothalamus did not alter body weight compared to control mice in either regular chow or high-fat, high-sugar diet, but mitochondria within astrocytes were fewer and smaller in response to elevated blood glucose levels (16) (Figure 1). HFD promoted loss of synapses on POMC neurons in the ARC due to reactive gliosis where glial ensheathment of the soma was increased (89). This altered synaptic organization led to increased POMC tone and a decrease in excitatory connections onto neighboring neuropeptide Y (NPY) cells.

These data highlight the role of astrocyte-neuronal crosstalk in energy homeostasis and how altered astrocyte function can affect mitochondrial networks in neurons. As yet, more work is needed to elucidate the role of mitochondrial dynamics and dysfunction in astrocytes and how these relate to whole body metabolism, feeding behavior, and hormone sensitivity in the hypothalamus and DVC.

Microglia are the immune cells of the central nervous system, acting to protect from invaders and orchestrating the inflammatory response. Three days of HFD in rats led to an increased number of microglia in the ARC compared to regular chow fed controls along with increased expression of inflammatory mediators including IL-6 and SOCS3 (77) (Figure 1). Central modulation of inflammation by inhibition of sodium-glucose transporter 2 (SLGT2) in obese insulinresistant mice blocks microglia activation in the hypothalamus and restores insulin sensitivity $(90,91)$. Microglia are crucial in the development of obesity and T2D as they initiate the inflammatory response following overnutrition and increased circulating free fatty acids (13).

Recently, mitochondrial dynamics in microglia have begun to be studied, primarily in the hypothalamus. Three days of HFD in mice led to an increase in activated DRP1 in hypothalamic microglia, and mitochondria were decreased in size and increased in number (15) (Figure 1). High-fat feeding also increased expression of the mitochondrial protein UCP2 (Uncoupling protein 2) in microglia (15). UCP2 plays a critical role in mitochondrial function, including control of ROS generation $(92,93)$ and is highly expressed in activated microglia (94). Selective deletion of $U c p 2$ in microglia of adult mice $\left(U c p 2^{\mathrm{MGKO}}\right)$ prevented changes to mitochondrial dynamics induced by HFD (15); mitochondria did not change in size, number or coverage. Ucp $2^{\mathrm{MGKO}}$ mice did not present with 
activated microglia in the ARC following HFD, and cytokine levels were reduced. Furthermore, Ucp $2^{\mathrm{MGKO}}$ mice were protected from diet-induced obesity; their food intake was reduced, energy expenditure increased, and insulin sensitivity improved compared to control mice on HFD. It has been previously reported that HFD alters POMC synaptic input organization via reactive gliosis (89), Ucp $2^{\mathrm{MGKO}}$ mice were protected, and synapses onto POMC cell bodies were increased along with increased POMC activation (15). This suggests that activated microglia may be upstream controllers of synaptic plasticity and astrogliosis in response to overfeeding and present a potential therapeutic avenue for alleviating obesity. As yet the effects of other mitochondrial proteins in the microglia have not been studied nor has the role of microglia in the DVC in DIO models.

\section{MITOCHONDRIAL DYNAMICS AND GLUCOSE METABOLISM IN THE BRAIN}

Glucose is the main fuel utilized by the brain where brain glucose metabolism also provides the energy and precursors for the biosynthesis of neurotransmitters (95); therefore, tight regulation of glucose homeostasis is essential to maintain blood glucose level for optimal brain and CNS function. Glucose is a large polar molecule which cannot easily pass the lipid cell membrane by simple diffusion; therefore, entry of glucose into the CNS and its cells are achieved by transport proteins known as glucose transporters $(96,97)$. Glucose transporters are comprised of two main types which include sodium-glucose linked transporters (SGLTs) which symport glucose across the cell membrane with $\mathrm{Na}^{+}$along a sodium gradient, and sodium-independent transporters (GLUTs), which transport glucose across the plasma membrane by a facilitated diffusion mechanism $(96,97)$. GLUT-1 is expressed by endothelial cells at the $\mathrm{BBB}$ and is the predominant transporter which is responsible for the movement of glucose into the brain (98), where it is then taken up by neurons and astrocytes which predominantly express GLUT3 and GLUT1, respectively (99101). While nearly all of the six identified SGLTs, apart from SGLT5, have been shown to be expressed in the brain; the distribution of SGLT expression and their contribution to glucose uptake differ strongly across the brain (102, 103). SGLT1 is the most studied of this family, where reports have shown that SGLT1 accounts for $80 \%$ of SGLT-mediated glucose uptake in the midbrain (102) and that $45 \%$ of GE-neurons tested in the ventromedial hypothalamus (VMH) are activated by an SGLT1-specific ligand (104).

Following entry to the CNS, the $\mathrm{MBH}$ and DVC sense glucose, circulating hormones including insulin, and nutrient availability to control CNS glucose levels and glucose metabolism by alterations in feeding behavior, HGP, and peripheral glucose uptake and utilization $(70,105)$. For some time, the intracellular mechanisms underlying the ability of these cells to sense, respond to, and influence changes in glucose homeostasis have been unclear. However, emerging research is beginning to show that the dynamic nature of mitochondria, their energy sensing properties, and their ability to undergo fusion and fission, may be critical for the ability of these cells to contribute to the central regulation of metabolism.

\section{GLUCOSE SENSING IN THE HYPOTHALAMUS}

The hypothalamus contains several nuclei which are involved in the central control of metabolism, including the ARC, ventromedial, paraventricular (PVN), and dorsomedial hypothalamus (DMH) (106) (Figures 2A-C). Specialized glucose sensing cells are present within hypothalamic nuclei which integrate and control neuroendocrine signaling and function and play an essential role in the regulation of systemic glucose levels, acting as a critical site for counterregulatory mechanisms in response to both hypo- and hyperglycemia (106-108).

Neurons in the ARC control systemic glucose levels by neural regulation of HGP (108), whereas glucose sensing neurons in the $\mathrm{VMH}$ prevent severe hypoglycemia by activating the counterregulatory response (CRR) which engages several defensive mechanisms to restore glucose homeostasis. Glucose sensing neurons detect changes in glucose levels either above or below $2.5 \mathrm{mM}$ (109) and respond to extracellular glucose concentration by changing their firing rate; glucose-excited (GE) cells increase their rate of neuronal firing, whereas glucose-inhibited (GI) cells decrease their firing when exposed to a rise in extracellular glucose $(107,110)$. Neuronal glucose responsiveness is associated with the activity of $\mathrm{K}_{\mathrm{ATP}}$ channels which couple the energy status of the cell and electrical activity, closing the channel and triggering depolarization in a high ATP/ADP ratio and opening the channel causing hyperpolarization in a low ATP/ ADP ratio $(111,112)$ (Figure 2Bii). In response to changing energy demand and supply, mitochondria adapt by changing the capacity and/or efficiency of ATP production which will therefore influence the activity of $\mathrm{K}_{\mathrm{ATP}}$ channels and neuronal activation of glucose sensitive cells.

Glucose transporters, both GLUTs and SGLTs, have also been implicated in hypothalamic glucose sensing. GLUT2 is required for glucose sensing in pancreatic $\beta$-cells and evidence suggests that it may also perform a similar role in the brain. For example, GLUT2 ShRNA induced impaired GLUT2 function in the ARC, blunted the increase in insulin secretion following administration of a glucose bolus and diminished glucoprivic feeding behavior $(113,114)$. Furthermore, transgenic mouse lines with either brainspecific GLUT2 deletion (115) or inhibition of GLUT2-mediated extracellular glucose detection $(116,117)$ also support the role of GLUT2 in hypothalamic glucose sensing and control of food intake. Another member of the GLUT family, GLUT4, has been implicated in glucose sensing, particularly as it is expressed in $57 \%$ of GE neurons and 63\% of GI neurons in the VMH (118). Indeed, it has been shown that the CRR to hypoglycemia is impaired in 


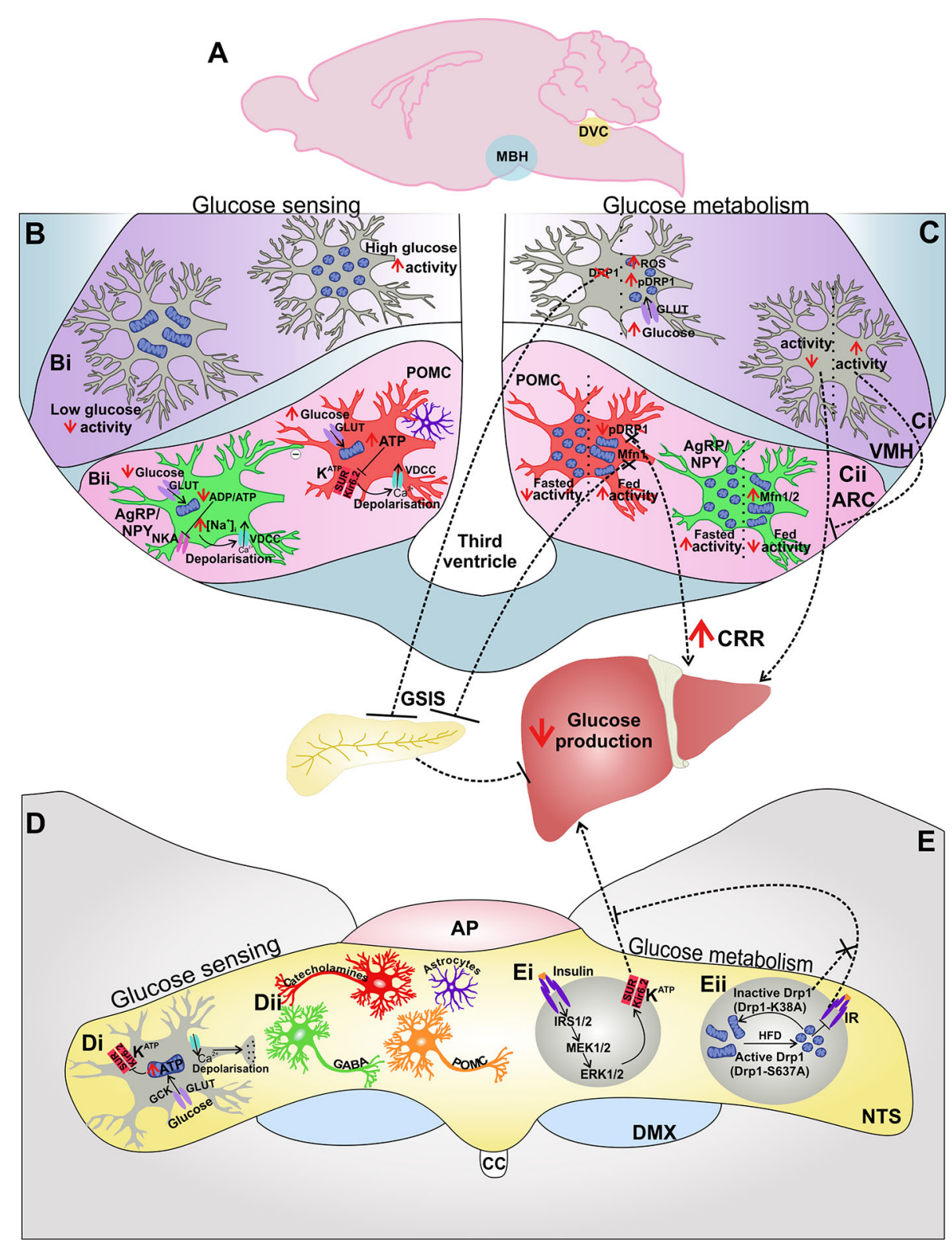

FIGURE 2 | The MBH and DVC are involved in central glucose sensing and control of glucose metabolism: The MBH and DVC are distinct areas which are involved in both glucose sensing and glucose metabolism (A). Glucose sensing cells in the MBH (B) are present in both the VMH (Bi) and ARC (Bii). In the VMH increased glucose leads to mitochondrial fission and increased neuronal activity (Bii). In the ARC, glucose-inhibited (GI) AgRP and glucose-excited (GE) POMC neurons utilize the $\mathrm{Na}^{+} / \mathrm{K}^{+}$-ATPase (NKA) or $\mathrm{K}_{\text {ATP }}$ channels in order to couple extracellular glucose levels and energy status with neuronal activity (Bii). Astrocytes also influence the activity of POMC neurons in response to changes in glucose availability (Bii). The MBH also influences glucose metabolism (C), where neuronal activity and increased mitochondrial fission and neuronal activity in VMH neurons induce glucose-stimulated insulin secretion (GSIS) from the pancreas and decrease glucose production (Ci). Mitochondrial dynamics in AgRP and POMC neurons in the ARC influence neuronal activity of these neurons in response to fasted vs fed states (Cii). Inhibition of mitochondrial fusion in POMC neurons inhibits GSIS (Cii). The DVC is also able to sense glucose (D), utilizing KATP channels to transduce changes in extracellular glucose levels and therefore energy availability to neuronal activity (Di). Various cells have been implicated in glucose sensing in the DVC, including catecholaminergic-, GABAergic-, POMC neurons, and astrocytes (Dii). The DVC also influences glucose metabolism (E) by insulin signaling mediated ERK1/2 activation of $\mathrm{K}_{\text {ATP }}$ which decreases glucose production (Ei). Mitochondrial fission inhibits insulin receptor signaling in the DVC and impairs DVC control of glucose homeostasis by inhibiting reduced HGP (Eii). Abbreviations: CRR, counter-regulatory response; GCK, glucokinase; GLUT, glucose transporter.

mice following brain-specific KO of GLUT4 (119). Conversely, a reduction in hypothalamic SGLT1 expression using ShRNA was found to improve the CRR to hypoglycemia, leading to enhanced HGP, showing that SGLT1 in the VMH is also involved in glucose sensing and regulation of glucose homeostasis (120). It would therefore seem that glucose transporters also contribute to the glucose sensing machinery in the hypothalamus, and further work is required to determine how glucose availability by glucose 
transport, glucose-sensing by the transporters themselves, and ATP production by mitochondria may be linked in the act of hypothalamic glucose sensing.

Astrocytes also play a crucial role in regulation of glucose homeostasis, modulating glucose availability, and therefore the levels of brain glucose metabolism, via control of glucose transport across the BBB by GLUT-1, which is highly expressed in astrocytes $(16,121)$. This is exemplified by the finding that IR-KO in GFAP ${ }^{+}$ astrocytes also resulted in reduced expression of GLUT1 and a concomitant reduction in CSF glucose concentration (16). As well as responding to insulin and leptin $(16,122)$, astrocytes also express receptors for the hormone glucagon-like peptide 1 (GLP-1) (123-125). Activation of GLP-1 receptors in astrocytes of the hypothalamus inhibited astrocytic glucose uptake and promoted fatty acid utilization (126). Furthermore, knockout of GLP-1 receptors from hypothalamic astrocytes abolished alterations in mitochondrial dynamics associated with acute glucose exposure ex vivo (126). In the ARC, ablation of astrocytic GLP-1 receptors in mice improved glucose availability and peripheral glucose metabolism (126), further highlighting the role for astrocytes in control of glucose homeostasis.

$\mathrm{AgRP}$ and POMC neurons of the ARC have opposing effects on glucose metabolism (127) (Figure 2Cii). The mechanisms which allow these two cell types to respond to, and influence, whole body energy status have been elusive. However, mitochondrial dynamics in both AgRP/NPY and POMC neurons have recently been shown to be regulated by nutrition in an opposing manner in these two cell types (62, 64) (Figure 2Cii). Changes in mitochondrial dynamics are involved in how these cells respond to glucose levels by altering neuronal activation and thereby influence systemic glucose metabolism.

\section{GLUCOSE SENSING AND POMC NEURONS}

Neuronal activity of anorexigenic POMC is influenced by extracellular glucose levels, where a subset of POMC neurons are $\mathrm{GE}(64,128,129)$. In the postprandial state, when extracellular glucose rises, $\mathrm{K}_{\mathrm{ATP}}$ channels in POMC neurons close, leading to depolarization and increased neuronal firing $(128,129)$ (Figure 2Bii). GE POMC neurons exhibit a $2.26+/-$ 0.23 -fold faster firing rate in $5 \mathrm{mM}$ glucose compared to $3 \mathrm{mM}$ glucose (129). Transgenic expression of a mutant Kir6.2 subunit in POMC neurons, which prevents ATP-mediated closure of $\mathrm{K}_{\mathrm{ATP}}$ channels, resulted in a failure of POMC neurons to increase their firing rate in response to high glucose levels and an impairment in the whole-body response to systemic glucose load (129). $\mathrm{K}_{\mathrm{ATP}}$ channel function is therefore required for activation of POMC neurons by glucose which contributes to the overall control of glucose homeostasis. Furthermore, although POMC neurons are clearly activated by glucose (129), it has been argued that no study has yet shown that glucose directly modulates the activity of these neurons (109). Instead, it has been hypothesized that glucose modulates synaptic remodeling to alter the frequency of excitatory postsynaptic currents onto POMC neurons (130), perhaps by retraction of glial coverage (131) (Figure 2Bii).

HFD decreases spontaneous activity and hyperpolarizes the membrane potential of POMC neurons $(68,132)$. Glucose responsiveness by POMC neurons is also abolished in obese mice following a HFD, which is linked to an increase in the mitochondrial protein UCP2. In pancreatic $\beta$-cells, UCP2 negatively controls glucose sensing by mediating proton leak across the inner mitochondrial membrane, decreasing the yield of ATP from glucose (133). In POMC neurons, UCP2 is also involved in diet-induced loss of glucose sensing, perhaps by decreasing ATP production by POMC neurons (129). Genetic knockdown of Ucp2 can prevent diet induced obesity and restore insulin sensitivity in leptin deficient $o b / o b$ mice $(129,133)$. These results highlight the importance of mitochondria in glucose sensing and illustrate that disruption of these processes following excessive energy intake may be an important pathogenic component in obesity associated loss of glucose and insulin sensitivity in T2D.

Astrocytes in the ARC also play a role in glucose metabolism by influencing POMC neuronal activity (16) (Figure 2Bii). Neurons make approximately $13 \%$ of the brains ATP from glucose which is transported across the $\mathrm{BBB}$; the remaining $87 \%$ is generated by glial cells (134). Therefore, together, astrocytes and neurons form a metabolic unit that is able to monitor circulating nutrients to alter food intake and energy homeostasis.

Inducible postnatal deletion of insulin receptor specifically in $\mathrm{GFAP}^{+}$astrocytes (GFAP-IR-KO) caused a loss insulin signaling activation of Akt in astrocytes with no effect on peripheral insulin signaling. Astrocyte-specific loss of insulin receptors decreased hypothalamic glucose sensing as GFAP-IR-KO blunted the activation of POMC neurons to cause an increase in systemic glucose levels (16). The mitochondria play a critical role in neuronal responses to fluctuations in nutrient availability by inducing alterations in the mitochondrial network of nutrient sensing neurons, including changes in mitochondrial morphology, mitochondrial density, and coverage, and the number of contacts between mitochondria and the ER (135, 136). For example, POMC neurons in GFAP-IR-KO mice exhibit decreased mitochondrial density and mitochondrial coverage in response to elevated glucose levels. Furthermore, in response to glucose administration, GFAP-IR-KO mice had higher numbers of ER-mitochondrial contacts in POMC neurons compared to WT mice (16). These results illustrate how insulin signaling in astrocytes is required for appropriate POMC neuronal function in response to cellular metabolic needs and show how astrocyteneuronal crosstalk in the ARC influences metabolic homeostasis.

\section{MITOCHONDRIAL DYNAMICS IN POMC NEURONS ASSOCIATED WITH GLUCOSE METABOLISM}

The mitochondria also act as energy sensors in anorexigenic POMC neurons in order to balance energy demand and nutrient supply, where food deprivation results in a decrease in 
mitochondrial density and coverage in POMC neurons (62) (Figure 2Cii). Conversely, mitochondria number is highest, and mitochondrial length and branching are decreased in POMC neurons in fed and diet-induced obese mice when compared to fasted or leptin deficient ob/ob animals $(64,137)$ (Figure 2Cii).

MFN1 has recently emerged as a nutrient sensor in POMC neurons which influences whole-body glucose metabolism as it plays a key role in the central control of insulin release. Structural and functional alterations in mitochondria were found in POMC neurons with selective deletion of $M f n 1$ (64). Furthermore, POMC $M f n 1 \mathrm{KO}$ impaired central glucose sensing, perturbed glucose-stimulated insulin secretion (GSIS), and altered glucose metabolism (65) (Figure 2Cii), indicating the importance of mitochondrial fusion in POMC-mediated glucose homeostasis.

During normal metabolism of oxygen by mitochondria, ROS are formed as a natural by-product (138). Release of ROS from POMC neurons is required for POMC neuronal activation in response to rising glucose levels $(139,140)$. ROS activate POMC neurons by modulation of membrane potential and neuronal firing to promote satiety and increase energy expenditure, for example ROS levels are significantly higher in POMC neurons following HFD feeding (137). Mitochondrial morphology is also associated with ROS production and energy status (141). MFN1 appears to be important for this process in POMC neurons, as $M f n 1$-specific $\mathrm{KO}$ in these cells results in increased mitochondrial respiration and ROS production in response to high glucose (65). Furthermore, transient excessive ROS production in POMC neurons leads to defective GSIS in POMCM $n 1 \mathrm{KO}$ mice as central administration of two chemically distinct ROS scavengers normalized GSIS in these animals (65). Loss of MFN1 in POMC neurons therefore impacts mitochondrial flexibility and interferes with POMC neuronal responses, hindering glucose sensing and sympathetic nervous system driven peripheral responses which modulate glucose metabolism such as insulin release.

The fusogenic protein MFN2 is also important for mitochondria-ER tethering (67). HFD results in a downregulation of $M f n 2$ expression, increased mitochondrial density, and decreased mitochondria-ER contacts in POMC neurons (64), illustrating that MFN2 is involved in metabolic alterations following diet-induced obesity and so may be involved in the central regulation of energy balance.

Whilst liver glucose output and expression of gluconeogenic genes were normal in POMCMfn1 KO loss of $M f n 2$ resulted in enhanced HGP. These changes were a result of alterations in mitochondrial morphology, reduced numbers of mitochondriaER contacts, and increased ER stress in POMC neurons. ER contact is needed for $\mathrm{Ca}^{2+}$ uptake in the mitochondria (67). Dietinduced obesity has been shown to reduce mitochondrial $\mathrm{Ca}^{2+}$ accumulation capacity in POMC neurons, leading to greater levels of free intracellular $\mathrm{Ca}^{2+}$ which contributes in part to a reduction in POMC neuronal excitability by activation of hyperpolarizing $\mathrm{Ca}^{2+}$-activated $\mathrm{K}^{+}$channels (68). It could therefore be hypothesized that reduced mitochondria-ER contact in POMCMfn $2 \mathrm{KO}$ mice also results in alterations in
POMC neuronal activity by changes in the levels of intracellular $\mathrm{Ca}^{2+}$; however, this remains to be determined.

These results show that like MFN1, MFN2 is also required for POMC neuronal function and systemic energy balance as it is critical for mitochondria-ER interaction (64). POMCMfn $1 K O$ was found to alter GSIS by increasing POMC ROS levels, $M f n 2$ deletion also increased ROS production, illustrating that there may also be some shared roles for MFN1 and MFN2 in POMC neuron function. Deletion of the other fusogenic protein Opa1 in POMC neurons failed to produce the same phenotypic features of either $M f n 1$ or $M f n 2 \mathrm{KO}$; these data therefore illustrate the importance of $M f n$-specific mitochondrial functions in POMC neurons for the regulation of whole-body energy/ glucose homeostasis.

The importance of mitochondrial fusion in the control of glucose sensing in POMC neurons is also clear when examining the role of the fission protein DRP1. Inducible deletion of Drp1 in mature POMC neurons improves their glucose responsiveness, as measured by stronger POMC neuronal inhibition in response to decreased extracellular glucose levels (63). This was paired with a significant improvement in peripheral glucose tolerance, an increase in food intake in response to glucoprivation, and enhanced hepatic counterregulatory responses to hypoglycemia (63) (Figure 2Cii). Glucose metabolism increases levels of POMC ROS and activation of the nuclear receptor Peroxisome proliferatoractivated receptor gamma (PPAR $\gamma$ ) which increases neuronal firing (137). This crucial process is also linked to Drp1-induced mitochondrial fission, as following exposure to rising glucose load, POMC neurons with Drp1 deletion showed increased levels of ROS and PPAR $\gamma$ protein levels alongside greater neuronal activation compared to control (63). Increased ROS and PPAR $\gamma$ levels in animals with POMC Drp1 deletion resulted in greater POMC neuronal activity in response to metabolic shifts by altering $\mathrm{K}_{\mathrm{ATP}}$ channel expression (63). These results show that DRP1-mediated mitochondrial fission plays a negative role in POMC neuronal responses to glucose load and further highlight that mitochondrial dynamism is critical for the central regulation of glucose metabolism.

\section{GLUCOSE SENSING IN AGRP NEURONS}

Much like in anorexigenic POMC neurons of the ARC, glucose is also an important regulator of AgRP/NPY neuronal activity. For example, I.P or ICV injection of glucose in rats produces a $1.8 \mathrm{mM}$ rise in circulating glucose and a 30-60\% reduction in NPY and AgRP mRNA in the ARC at 30- and 60-min post injection. After 90 min circulating glucose levels decline, and the suppressive effect of glucose administration is lost, while NPY and AgRP levels increase by $50 \%$ (142). These results illustrate that AgRP/NPY neurons are sensitive to changes in circulating glucose levels and respond accordingly to modulate energy balance by altering levels of AgRP and NPY which influence energy intake and expenditure (143-145). Half of AgRP/NPY expressing neurons of the ARC are inhibited by physiological brain glucose levels (146). In response to 
decreased glucose levels AgRP/NPY neurons are activated, leading to increased $c$-fos expression, enhanced hypothalamic NPY release, depolarization and greater neuronal firing, and a concurrent drive to feed when there is an energy deficit (147-149). A recent study using NPY-deficient mice found that NPY is necessary for the immediate feeding behavior and acute glucose homeostasis functions which are governed by AgRP/NPY neuron activation (150).

While the exact mechanism by which decreased glucose induces depolarization in $\mathrm{AgRP} / \mathrm{NPY}$ neurons is yet to be determined, the $\mathrm{Na}^{+} / \mathrm{K}^{+}$-ATPase (NKA) pump has been evidenced as one of the molecules which converts low glucose levels to changes in neuronal excitability in glucose sensitive cells (Figure 2Bii). Fasting glucose levels suppress the enzymatic activity of NKA by decreasing ATP-hydrolyzing activity by half and ATP substrate availability by a third (151). These changes lead to depolarization of GI AgRP/NPY neurons via an increase in the level of intracellular $\mathrm{Na}^{+}$, illustrating how suppression of NKA by decreased ATP availability in negative energy states is tightly linked to AgRP/NPY activation (152) (Figure 2Bii). In contrast, changes in the activity of the energy sensor AMP-activated protein kinase (AMPK) has been shown to be required for hyperpolarization and therefore inactivity of GI neurons following exposure to glucose $(152,153)$. AgRP/NPY neurons also play a fundamental role in mediating the central inhibitory effect of insulin on HGP $(55,154)$, thereby illustrating the dual role AgRP/NPY neurons play in modulating whole body energy balance by responding to both insulin and glucose.

\section{MITOCHONDRIAL DYNAMICS IN AGRP/ NPY NEURONS ASSOCIATED WITH GLUCOSE METABOLISM}

As in POMC neurons, mitochondria also act as energy sensors in AgRP/NPY neurons; however, the electrical and mitochondrial morphological responses of AgRP/NPY neurons to nutrition oppose those of POMC neurons. By sensing changes in extracellular glucose levels neuronal activity of AgRP/NPY neurons is increased during periods of fasting or negative energy balance $(155,156)$. There are also parallel changes in mitochondrial morphology in these neurons; for example, in fasted states mitochondria in AgRP/NPY are decreased in size, and mitochondrial density is increased $(62,157)$ (Figure 2Cii). These changes are indicative of increased levels of mitochondrial fission and suggest that fission may be a requirement for the activation of orexigenic AgRP/NPY in times of negative energy balance. Indeed, expression of the key fission protein Drp1 has been found in AgRP/NPY neurons (62). However, as yet, no studies have examined the effect of Drp1 KO in AgRP/NPY neurons upon glucose sensing and metabolism. It would therefore be interesting to see whether impairment of Drp1-dependent mitochondrial fission decreases glucose responsiveness and prevents increased neuronal activity in response to negative energy balance in AgRP/NPY neurons, particularly as Drp1 $\mathrm{KO}$ improved neuronal glucose responsiveness in POMC neurons (63).
Paradoxically, in HFD-fed mice AgRP neurons are highly active (137) and exert a greater inhibitory tone upon anorexigenic POMC neurons (158). AgRP/NPY neurons are normally GI; however, when exposed to HFD, these neurons show an increase in electrical activity in response to elevated levels of glucose (62). Mitochondria in AgRP neurons following HFD feeding were found to be significantly larger; however, mitochondrial density was decreased, indicating that nutrient excess in HFD leads to increased fusion in AgRP neurons (62). Deletion of $M f n 1$ or $M f n 2$ in AgRP/NPY neurons prevents fusion and impairs neuronal firing frequency in diet-induced obesity (62), illustrating that the induction of mitochondrial fusion is required for the paradoxical neuronal activation of AgRP/NPY neurons following exposure to HFD (Figure 2Cii). Impaired neuronal activity of $M f n$-deficient AgRP/NPY neurons was a result of altered intracellular ATP levels as cell-selective administration of ATP restored AgRP/NPY neuronal activity (62). Mfn2-KO mice fed HFD also had improved glucose tolerance, demonstrating the importance of mitochondria in whole body metabolic responses to positive energy balance. Such results therefore show how mitochondrial fission and fusion in AgRP/NPY neurons are dynamically regulated by nutritional and metabolic status and contribute to whole-body energy metabolism.

\section{GLUCOSE SENSING IN THE VENTROMEDIAL HYPOTHALAMUS}

The VMH also contains glucose sensing neurons and is another key area which is involved in the control of glucose homeostasis $(118,159,160)$ (Figure 2Bi). Much like in the ARC, recent work has also illustrated that DRP1-mediated mitochondrial fission is essential for glucose sensing in the $\mathrm{VMH}$ and is therefore involved in how the VMH regulates systemic glucose metabolism (161163) (Figure 2Ci). However, unlike in POMC neurons, Drp1 positively regulates glucose responsiveness of $\mathrm{VMH}$ neurons $(161,162)$.

Systemic administration of glucose decreased mitochondrial size and increased mitochondrial density without affecting total mitochondrial area in VMH neurons which is suggestive of glucose-induced mitochondrial fission (162) (Figure 2Ci). Indeed, the ratio of active phosphorylated DRP1 to nonphosphorylated DRP1 was significantly greater in VMH neurons following glucose infusion, confirming glucose-induced mitochondrial fission in these cells (162) (Figure 2Ci). Increases in extracellular glucose induce an increase in DRP1 translocation to mitochondria in the $\mathrm{VMH}$; inhibition of this process blocks mitochondrial ROS production in response to glucose and impairs hypothalamic glucose sensing induced insulin secretion. Mitochondrial ROS production by DRP1-mediated mitochondrial fission in the VMH is also required for the satiation effect of intracarotid glucose infusion (161) (Figure 2Ci).

Impairment of hypothalamic glucose sensing and central GSIS has been described in animals fed a hypercaloric high-fat highsugar (HFHS) diet for 3 weeks (163). HFHS-fed animals failed to increase mitochondrial ROS levels in response to an increase in 
glucose, where inhibition of mitochondria by rotenone treatment restored both ROS levels and hypothalamic glucose sensing induced insulin secretion in HFHS-fed animals. These HFHS diet-induced features were associated with a disruption in translocation of DRP1 to mitochondria in the hypothalamus in response to CNS hyperglycemia, further illustrating that DRP1mediated mitochondrial fission and ROS production are important for regulating glucose metabolism by the VMH and can be impaired by caloric excess $(161,163)$.

Activation of DRP1 in the VMH is dependent upon the mitochondrial protein UCP2, as phosphorylation of DRP1 and therefore glucose-mediated mitochondrial fission, was absent in Ucp2 KO mice (162). UCP2 has also been shown to modulate neuronal activity in part by controlling ROS production (164). UCP2 negatively regulates mitochondrial ROS production, where ROS levels in VMH neurons are involved in mediating GSIS in response to systemic glucose load $(137,161,162)$. VMH neurons with $U c p 2 \mathrm{KO}$ responded to glucose administration with an increased level of ROS compared to control animals; selective re-expression of UCP2 in the VMH restored ROS levels, illustrating that UCP2 enables $\mathrm{VMH}$ neuronal activation in response to rising glucose by buffering ROS. Ucp2 $\mathrm{KO}$ animals were also glucose intolerant and exhibited reduced insulin sensitivity; these changes were also restored by re-expression of UCP2 in VMH neurons (162). Such results illustrate how UCP2 influences mitochondrial dynamics and neuronal activity in the $\mathrm{VMH}$ which are crucial for the regulation of glucose metabolism.

In conclusion mitochondrial dynamism in hypothalamic nuclei such as the ARC and the VMH is essential for the control of glucose homeostasis and the maintenance of energy balance (Figure 2C). Mitochondria are unique energy sensors, where alterations in mitochondrial products such as ATP, UCP2, or ROS influence the neuronal activity of glucose sensing cells in the hypothalamus, which in turn influences energy balance.

\section{GLUCOSE SENSING AND MITOCHONDRIAL DYNAMICS IN THE DVC}

Although much of the work regarding the CNS control of metabolism and energy balance has concentrated on the hypothalamus, the DVC of the brainstem is the first site for the sensing and integration of peripheral neurochemical and humoral signals which communicate energy status to the brain $(70,165)$. Much like in the hypothalamus, glucose responsive cells are present in all three nuclei of the DVC (166); the DVC is therefore able to regulate glucose homeostasis by the CRR and is also able to influence HGP via DVC-hepatic vagal efferent neural circuitry $(71,167)$ (Figures 2D, E). The NTS also contains neurons that are activated by gastric distension; this acts as a postprandial satiety signal which reaches the NTS via vagal afferent fibers from the gut $(168,169)$.

The NTS is anatomically well situated to be influenced by dynamic changes in plasma glucose concentrations due its proximity to the AP, which is a circumventricular organ, and the presence of fenestrated capillaries within the NTS (170). It has long been known that the NTS contains cells which are gluco-responsive $(166,171)$. A subset of NTS neurons show depolarizing or hyperpolarizing responses to an increase or decrease in extracellular glucose concentration and are also involved in the CRR to hypoglycemia (172-176). NTS neurons respond to increased levels of glucose in a similar way to those in the hypothalamus which are mechanistically similar to pancreatic $\beta$-cells. These cells employ glucokinase (GCK) to monitor changes in glucose availability and mediate cellular utilization of glucose, GCK therefore links increased glucose to changes in membrane potential which occur via glucokinasedependent modulation of $\mathrm{K}_{\mathrm{ATP}}$ channels $(172,175,177)$ (Figure 2Di). For example, $\mathrm{K}_{\mathrm{ATP}}$ antagonists blunt the responsiveness of these NTS neurons to increased glucose $(175,177)$. It has also been shown that $\mathrm{K}_{\mathrm{ATP}}$ channels of NTS neurons which respond to reductions in extracellular glucose levels, i.e. GI NTS neurons, are blocked by hyperglycemia and so blunt the neuronal response to low glucose levels (172). Therefore, in response to hyperglycemia, these GI NTS neurons lose the ability to respond to fast reductions in glucose, where pathological prolonged hyperglycemia such as in diabetes, may negatively impact the energy sensing abilities of $\mathrm{K}_{\mathrm{ATP}}$ channels in the NTS (172).

There have been several neuronal types which have been identified as NTS glucose sensing neuronal candidates which play a role in regulating glucose metabolism. These include GLUT2 $^{+}$GABAergic neurons which control vagal output and glucagon secretion $(174,177,178)$, catecholaminergic neurons which mediate hypoglycemic hunger $(179,180)$, and NTS POMC neurons which are involved in short-term changes in feeding control $(181,182)$ (Figure 2Dii). Astrocytes in the NTS have also been shown to sense glucose and contribute to whole body energy balance by regulation of the hypoglycemia-induced counter-regulatory response $(12,183,184)$ (Figure 2Dii). While much work has illustrated that mitochondria and mitochondrial dynamics are essential for the hypothalamic control of glucose homeostasis and that the NTS also influences energy balance by glucose sensing, how mitochondria are involved in these processes in the DVC is currently unknown.

The NTS is also able to sense insulin and responds to acute insulin by lowering HGP and regulating food intake and body weight via an insulin-ERK1/2 mediated signaling cascade which activates $\mathrm{K}_{\mathrm{ATP}}$ channels in the $\operatorname{DVC}(70,71)$ (Figure 2Ei). Activation of $\mathrm{K}_{\mathrm{ATP}}$ channels is sufficient to induce a reduction in HGP and highlight the energy sensing abilities of $K_{\mathrm{ATP}}$ in the DVC which therefore influence whole body glucose metabolism (70). HFD feeding, or adenoviral-mediated constitutive activation of DRP1 (Drp1-S637A), results in a loss of the glucoregulatory effect of DVC insulin infusion $(70,72)$, where adenoviral-mediated molecular inhibition of DRP1-mediated mitochondrial fission by expression of a dominant negative form of DRP1 (Drp1-K38A) was found to restore the glucoregulatory effect of DVC insulin (72) (Figure 2Eii). These HFD-induced alterations in the mitochondria and insulin sensitivity in the DVC therefore require increased DRP1dependent mitochondrial fission, where a HFD-fed phenotype could be recapitulated by adenoviral expression of a constitutively active form of DRP1, indicating that dietinduced changes in mitochondrial dynamism negatively affect 
central insulin sensitivity and HGP (Figure 2Eii). In summary, these results show that mitochondria in the DVC are essential for changes in peripheral glucose metabolism in response to DVC insulin sensing and illustrate how the DVC is a key area in the control of glucose homeostasis.

\section{MITOCHONDRIAL DYNAMICS ELSEWHERE IN THE BRAIN}

While this review has focused on the role of mitochondrial dynamics in the hypothalamus and DVC in metabolism, the influence of mitochondria on CNS function throughout the brain has been studied. Mitochondrial dynamics are involved in a number of neurodegenerative conditions including Alzheimer's disease, Parkinson's disease, Huntington's disease, and amyotrophic lateral sclerosis (ALS) [reviewed in (185-188)]. Indeed, obesity and diabetes are known to increase the risk of dementia $(189,190)$. Brain mitochondrial dysfunction in obesity and diabetes is associated with inflammation, ER stress, oxidative stress, all of which can exacerbate neurodegeneration. Upregulation of the fusion regulator OPA1 confers a protective effect in cerebellar granular neurons following excitotoxic insult (191), while ablation of DRP1 from forebrain neurons leads to hippocampal atrophy (192). Furthermore, mitochondria are transferred to adjacent neurons following focal cerebral ischemia, and inhibition of transfer worsened neurological outcomes (193). This suggests that the transfer of functional mitochondria from astrocytes to neurons after stroke supports cell viability and recovery. Such a mechanism may even occur in response to the chronic low-grade inflammation in obesity and diabetes in an attempt to protect neurons and therefore warrants further investigation.

\section{CONCLUSION AND FUTURE PERSPECTIVES}

While we have some understanding of how mitochondrial dynamics in the brain are associated with food intake and glucose sensing, there are still many more questions to be answered. The cell types involved in the hypothalamus have begun to be dissected, but as yet there is little data on the roles of specific cells in the DVC, and indeed for both regions the role of

\section{REFERENCES}

1. Chang CR, Blackstone C. Dynamic regulation of mitochondrial fission through modification of the dynamin-related protein Drp1. Ann NY Acad Sci (2010) 1201:34-9. doi: 10.1111/j.1749-6632.2010.05629.x

2. Youle RJ, Van Der Bliek AM. Mitochondrial fission, fusion, and stress. Science (80- ) (2012) 337:1062-65. doi: 10.1126/science.1219855

3. Kalia R, Wang RYR, Yusuf A, Thomas PV, Agard DA, Shaw JM, et al. Structural basis of mitochondrial receptor binding and constriction by DRP1. Nature (2018) 558:401-5. doi: 10.1038/s41586-018-0211-2

4. Ji W, Hatch AL, Merrill RA, Strack S, Higgs HN. Actin filaments target the oligomeric maturation of the dynamin GTPase Drp1 to mitochondrial fission sites. Elife (2015) 4:e11553. doi: 10.7554/eLife.11553 mitochondria in astrocytes and microglia needs to be further explored. Mitofusins and OPA1 also need to be studied in the DVC in relation to overnutrition, obesity, and T2D. This review has focused on diet-induced obesity and T2D; the genetic etiology of obesity remains unknown, but genome wide association studies (GWAS) of T2D have identified variants associated with T2D (194). Future studies may investigate the role of specific variants and what effects these have on mitochondria in cells of the brain as well as physiological effects on whole body metabolism. Finally, while mitochondrial dynamics are being studied in relation to obesity and T2D, changes to mitochondrial bioenergetics in the brain in these conditions remain unknown and warrant future investigation.

A fine balance of mitochondrial network dynamics is required for healthy brain function, T2D and obesity are modifiable risk factors that if ameliorated could reduce the risk of developing neurodegenerative comorbidities, and targeting mitochondrial dysfunction in the brain could be the link between these disorders. It is clear that mitochondria are crucial in the development and maintenance of obesity and T2D, playing a role in the control of glucose homeostasis and whole-body metabolism across cell types in the hypothalamus and DVC.

\section{AUTHOR CONTRIBUTIONS}

$\mathrm{JH}$ and LN contributed to the initial concepts and wrote the manuscript. BF contributed to the initial concepts and revised the manuscript. All authors contributed to the article and approved the submitted version.

\section{FUNDING}

Our lab is funded by: Royal Society (RG160605), Diabetes UK (2338) and Wellcome Trust (UNS63234). BF is supported an MRC-Career Development Fellowship (MR/S007288/1).

\section{ACKNOWLEDGMENTS}

We would like to thank Bianca Patel for insightful discussions during putting together and writing the review.

5. Chen H, Detmer SA, Ewald AJ, Griffin EE, Fraser SE, Chan DC. Mitofusins Mfn1 and Mfn2 coordinately regulate mitochondrial fusion and are essential for embryonic development. J Cell Biol (2003) 160:189-200. doi: 10.1083/ jcb. 200211046

6. Song Z, Ghochani M, McCaffery JM, Frey TG, Chan DC. Mitofusins and OPA1 mediate sequential steps in mitochondrial membrane fusion. Mol Biol Cell (2009) 20:3525-32. doi: 10.1091/mbc.E09-03-0252

7. Cipolat S, Martins de Brito O, Dal Zilio B, Scorrano L. OPA1 requires mitofusin 1 to promote mitochondrial fusion. Proc Natl Acad Sci USA (2004) 101:15927-32. doi: 10.1073/pnas.0407043101

8. Wakabayashi J, Zhang Z, Wakabayashi N, Tamura Y, Fukaya M, Kensler TW, et al. The dynamin-related GTPase Drp1 is required for embryonic and brain development in mice. J Cell Biol (2009) 186:805-16. doi: 10.1083/ jcb.200903065 
9. Ishihara N, Nomura M, Jofuku A, Kato H, Suzuki SO, Masuda K, et al. Mitochondrial fission factor Drp1 is essential for embryonic development and synapse formation in mice. Nat Cell Biol (2009) 11:958-66. doi: 10.1038/ ncb1907

10. Davies VJ, Hollins AJ, Piechota MJ, Yip W, Davies JR, White KE, et al. Opal deficiency in a mouse model of autosomal dominant optic atrophy impairs mitochondrial morphology, optic nerve structure and visual function. Hum Mol Genet (2007) 16:1307-18. doi: 10.1093/hmg/ddm079

11. Haddad-Tóvolli R, Dragano NRV, Ramalho AFS, Velloso LA. Development and function of the blood-brain barrier in the context of metabolic control. Front Neurosci (2017) 11:224. doi: 10.3389/fnins.2017.00224

12. MacDonald AJ, Holmes FE, Beall C, Pickering AE, Ellacott KLJ. Regulation of food intake by astrocytes in the brainstem dorsal vagal complex. Glia (2020) 68:1241-54. doi: 10.1002/glia.23774

13. Valdearcos M, Douglass JD, Robblee MM, Dorfman MD, Stifler DR, Bennett ML, et al. Microglial Inflammatory Signaling Orchestrates the Hypothalamic Immune Response to Dietary Excess and Mediates Obesity Susceptibility. Cell Metab (2017) 26:185-97. doi: 10.1016/j.cmet.2017. 05.015

14. García-Cáceres C, Fuente-Martín E, Argente J, Chowen JA. Emerging role of glial cells in the control of body weight. Mol Metab (2012) 1:37-46. doi: 10.1016/j.molmet.2012.07.001

15. Kim JD, Yoon A, Jin S, Correspondence SD, Yoon NA, Diano S. Microglial UCP2 Mediates Inflammation and Obesity Induced by High-Fat Feeding Cell Metabolism Article Microglial UCP2 Mediates Inflammation and Obesity Induced by High-Fat Feeding. Cell Metab (2019) 30:952-62. doi: 10.1016/j.cmet.2019.08.010

16. García-Cáceres C, Quarta C, Varela L, Gao Y, Gruber T, Legutko B, et al. Astrocytic Insulin Signaling Couples Brain Glucose Uptake with Nutrient Availability. Cell (2016) 166:867-80. doi: 10.1016/j.cell.2016.07.028

17. Burgos-Morón E, Abad-Jiménez Z, Marañón A, Iannantuoni F, EscribanoLópez I, López-Domènech S, et al. Relationship Between Oxidative Stress, ER Stress, and Inflammation in Type 2 Diabetes: The Battle Continues. JClin Med (2019) 8:1385. doi: 10.3390/jcm8091385

18. Woo CY, Jang JE, Lee SE, Koh EH, Lee KU. Mitochondrial dysfunction in adipocytes as a primary cause of adipose tissue inflammation. Diabetes Metab J (2019) 43:247-56. doi: 10.4093/dmj.2018.0221

19. Lumeng CN, Saltiel AR. Inflammatory links between obesity and metabolic disease. J Clin Invest (2011) 121:2111-7. doi: 10.1172/JCI57132

20. Reilly SM, Saltiel AR. Adapting to obesity with adipose tissue inflammation. Nat Rev Endocrinol (2017) 13:633-43. doi: 10.1038/ nrendo.2017.90

21. Bonnard C, Durand A, Peyrol S, Chanseaume E, Chauvin MA, Morio B, et al. Mitochondrial dysfunction results from oxidative stress in the skeletal muscle of diet-induced insulin-resistant mice. J Clin Invest (2008) 118:789800. doi: 10.1172/JCI32601

22. Yuzefovych L, Wilson G, Rachek L. Different effects of oleate vs. palmitate on mitochondrial function, apoptosis, and insulin signaling in L6 skeletal muscle cells: Role of oxidative stress. Am J Physiol - Endocrinol Metab (2010) 299. doi: 10.1152/ajpendo.00238.2010

23. Serra D, Mera P, Malandrino MI, Mir JF, Herrero L. Mitochondrial fatty acid oxidation in obesity. Antioxid Redox Signal (2013) 19:269-84. doi: 10.1089/ ars.2012.4875

24. Breininger SP, Malcomson FC, Afshar S, Turnbull DM, Greaves L, Mathers JC. Effects of obesity and weight loss on mitochondrial structure and function and implications for colorectal cancer risk. In: Proceedings of the Nutrition Society. Cambridge University Press (2019). p. 426-37. doi: 10.1017/S0029665119000533

25. Ma W, Yuan L, Yu H, Xi Y, Xiao R. Mitochondrial dysfunction and oxidative damage in the brain of diet-induced obese rats but not in diet-resistant rats. Life Sci (2014) 110:53-60. doi: 10.1016/j.lfs.2014.07.018

26. Brehm A, Krssak M, Schmid AI, Nowotny P, Waldhäusl W, Roden M. Increased lipid availability impairs insulin-stimulated ATP synthesis in human skeletal muscle. Diabetes (2006) 55:136-40. doi: 10.2337/ diabetes.55.01.06.db05-1286

27. Carlsen H, Haugen F, Zadelaar S, Kleemann R, Kooistra T, Drevon CA, et al. Diet-induced obesity increases NF-KB signaling in reporter mice. Genes Nutr (2009) 4:215-22. doi: 10.1007/s12263-009-0133-6
28. Zhang X, Zhang G, Zhang H, Karin M, Bai H, Cai D. Hypothalamic IKKß/ NF-KB and ER Stress Link Overnutrition to Energy Imbalance and Obesity. Cell (2008) 135:61-73. doi: 10.1016/j.cell.2008.07.043

29. Thaler JP, Schwartz MW. Minireview: Inflammation and obesity pathogenesis: The hypothalamus heats up. Endocrinology (2010) 151:4109-15. doi: 10.1210/en.2010-0336

30. Khan IM, Perrard XYD, Brunner G, Lui H, Sparks LM, Smith SR, et al. Intermuscular and perimuscular fat expansion in obesity correlates with skeletal muscle $\mathrm{T}$ cell and macrophage infiltration and insulin resistance. Int J Obes (2015) 39:1607-18. doi: 10.1038/ijo.2015.104

31. Varma V, Yao-Borengasser A, Rasouli N, Nolen GT, Phanavanh B, Starks T, et al. Muscle inflammatory response and insulin resistance: Synergistic interaction between macrophages and fatty acids leads to impaired insulin action. Am J Physiol - Endocrinol Metab (2009) 296. doi: 10.1152/ ajpendo.90885.2008

32. Boon MR, Bakker LEH, Haks MC, Quinten E, Schaart G, Van Beek L, et al. Short-term high-fat diet increases macrophage markers in skeletal muscle accompanied by impaired insulin signalling in healthy male subjects. Clin Sci (2015) 128:143-51. doi: 10.1042/CS20140179

33. Hirosumi J, Tuncman G, Chang L, Görgün CZ, Uysal KT, Maeda K, et al. Hotamisligil GS. A central, role for JNK in obesity and insulin resistance. Nature (2002) 420:333-6. doi: 10.1038/nature01137

34. Salvadó L, Palomer X, Barroso E, Vázquez-Carrera M. Targeting endoplasmic reticulum stress in insulin resistance. Trends Endocrinol Metab (2015) 26:438-48. doi: 10.1016/j.tem.2015.05.007

35. Lenin R, Sankaramoorthy A, Mohan V, Balasubramanyam M. Altered immunometabolism at the interface of increased endoplasmic reticulum (ER) stress in patients with type 2 diabetes. J Leukoc Biol (2015) 98:615-22. doi: 10.1189/jlb.3a1214-609r

36. Boden G, Duan X, Homko C, Molina EJ, Song W, Perez O, et al. Increase in endoplasmic reticulum stress-related proteins and genes in adipose tissue of obese, insulin-resistant individuals. Diabetes (2008) 57:2438-44. doi: $10.2337 / \mathrm{db} 08-0604$

37. Papa FR. Endoplasmic reticulum stress, pancreatic $\beta$-cell degeneration, and diabetes. Cold Spring Harb Perspect Med (2012) 2:a007666. doi: 10.1101/ cshperspect.a007666

38. Lee J, Ozcan U. Unfolded protein response signaling and metabolic diseases. J Biol Chem (2014) 289:1203-11. doi: 10.1074/jbc.R113.534743

39. Kawasaki N, Asada R, Saito A, Kanemoto S, Imaizumi K. doi: 10.1038/ srep00799

40. Bobrovnikova-Marjon E, Pytel D, Riese MJ, Vaites LP, Singh N, Koretzky GA, et al. PERK Utilizes Intrinsic Lipid Kinase Activity To Generate Phosphatidic Acid, Mediate Akt Activation, and Promote Adipocyte Differentiation. Mol Cell Biol (2012) 32:2268-78. doi: 10.1128/mcb.00063-12

41. Brown M, Dainty S, Strudwick N, Mihai AD, Watson JN, Dendooven R, et al. Endoplasmic reticulum stress causes insulin resistance by inhibiting delivery of newly synthesised insulin receptors to the cell surface. Mol Biol Cell (2020) 2:a007666. doi: 10.1091/mbc.E18-01-0013. mbc.E18-01-0013.

42. Park S, Aintablian A, Coupe B, Bouret SG. The endoplasmic reticulum stress-autophagy pathway controls hypothalamic development and energy balance regulation in leptin-deficient neonates. Nat Commun (2020) 11:1914. doi: 10.1038/s41467-020-15624-y

43. Kelley DE, He J, Menshikova EV, Ritov VB. Dysfunction of mitochondria in human skeletal muscle in type 2 diabetes. Diabetes (2002) 51:2944-50. doi: 10.2337/diabetes.51.10.2944

44. Bach D, Naon D, Pich S, Soriano FX, Vega N, Rieusset J, et al. Expression of $\mathrm{Mfn} 2$, the Charcot-Marie-Tooth neuropathy type 2A gene, in human skeletal muscle: Effects of type 2 diabetes, obesity, weight loss, and the regulatory role of tumor necrosis factor $\alpha$ and interleukin-6. Diabetes (2005) 54:2685-93. doi: 10.2337/diabetes.54.9.2685

45. Bach D, Pich S, Soriano FX, Vega N, Baumgartner B, Oriola J, et al. Mitofusin-2 determines mitochondrial network architecture and mitochondrial metabolism: A novel regulatory mechanism altered in obesity. J Biol Chem (2003) 278:17190-7. doi: 10.1074/jbc.M212754200

46. Jheng H-F, Tsai P-J, Guo S-M, Kuo L-H, Chang C-S, Su I-J, et al. Mitochondrial Fission Contributes to Mitochondrial Dysfunction and Insulin Resistance in Skeletal Muscle. Mol Cell Biol (2012) 32:309-19. doi: $10.1128 / \mathrm{mcb} .05603-11$ 
47. Vial G, Dubouchaud H, Couturier K, Cottet-Rousselle C, Taleux N, Athias A, et al. Effects of a high-fat diet on energy metabolism and ROS production in rat liver. J Hepatol (2011) 54:348-56. doi: 10.1016/j.jhep.2010.06.044

48. Yu T, Robotham JL, Yoon Y. Increased production of reactive oxygen species in hyperglycemic conditions requires dynamic change of mitochondrial morphology. Proc Natl Acad Sci USA (2006) 103:2653-8. doi: 10.1073/ pnas.0511154103

49. Qatanani M, Tan Y, Dobrin R, Greenawalt DM, Hu G, Zhao W, et al. Inverse regulation of inflammation and mitochondrial function in adipose tissue defines extreme insulin sensitivity in morbidly obese patients. Diabetes (2013) 62:855-63. doi: 10.2337/db12-0399

50. Choo HJ, Kim JH, Kwon OB, Lee CS, Mun JY, Han SS, et al. Mitochondria are impaired in the adipocytes of type 2 diabetic mice. Diabetologia (2006) 49:784-91. doi: 10.1007/s00125-006-0170-2

51. Myers MG, Olson DP. Central nervous system control of metabolism. Nature (2012) 491:357-63. doi: 10.1038/nature11705

52. Tong Q, Ye CP, Jones JE, Elmquist JK, Lowell BB. Synaptic release of GABA by AgRP neurons is required for normal regulation of energy balance. Nat Neurosci (2008) 11:998-1000. doi: 10.1038/nn.2167

53. Miki T, Liss B, Minami K, Shiuchi T, Saraya A, Kashima Y, et al. ATPsensitive $\mathrm{K}+$ channels in the hypothalamus are essential for the maintenance of glucose homeostasis. Nat Neurosci (2001) 4:507-12. doi: 10.1038/87455

54. Obici S, Zhang BB, Karkanias G, Rossetti L. Hypothalamic insulin signaling is required for inhibition of glucose production. Nat Med (2002) 8:1376-82. doi: $10.1038 / \mathrm{nm} 798$

55. Könner AC, Janoschek R, Plum L, Jordan SD, Rother E, Ma X, et al. Insulin Action in AgRP-Expressing Neurons Is Required for Suppression of Hepatic Glucose Production. Cell Metab (2007) 5:438-49. doi: 10.1016/ j.cmet.2007.05.004

56. Brown LM, Clegg DJ, Benoit SC, Woods SC. Intraventricular insulin and leptin reduce food intake and body weight in C57BL/6J mice. Physiol Behav (2006) 89:687-91. doi: 10.1016/j.physbeh.2006.08.008

57. Elias CF, Aschkenasi C, Lee C, Kelly J, Ahima RS, Bjorbæk C, et al. Leptin differentially regulates NPY and POMC neurons projecting to the lateral hypothalamic area. Neuron (1999) 23:775-86. doi: 10.1016/S0896-6273(01) 80035-0

58. Berglund ED, Vianna CR, Donato J, Kim MH, Chuang JC, Lee CE, et al. Direct leptin action on POMC neurons regulates glucose homeostasis and hepatic insulin sensitivity in mice. J Clin Invest (2012) 122:1000-9. doi: 10.1172/JCI59816

59. Caron A, Lemko HMD, Castorena CM, Fujikawa T, Lee S, Lord CC, et al. POMC neurons expressing leptin receptors coordinate metabolic responses to fasting via suppression of leptin levels. Elife (2018) 7:e33710. doi: 10.7554/ eLife. 33710

60. Wang J, Obici S, Morgan K, Barzilai N, Feng Z, Rossetti L. Overfeeding rapidly induces leptin and insulin resistance. Diabetes (2001) 50:2786-91. doi: $10.2337 /$ diabetes.50.12.2786

61. Cunarro J, Casado S, Lugilde J, Tovar S. Hypothalamic mitochondrial dysfunction as a target in obesity and metabolic disease. Front Endocrinol (Lausanne) (2018) 9:283. doi: 10.3389/fendo.2018.00283

62. Dietrich MO, Liu ZW, Horvath TL. Mitochondrial dynamics controlled by mitofusins regulate agrp neuronal activity and diet-induced obesity. Cell (2013) 155:188-99. doi: 10.1016/j.cell.2013.09.004

63. Santoro A, Campolo M, Liu C, Sesaki H, Meli R, Liu Z-W, et al. DRP1 Suppresses Leptin and Glucose Sensing of POMC Neurons. Cell Metab (2017) 25:647-60. doi: 10.1016/j.cmet.2017.01.003

64. Schneeberger M, Dietrich MO, Sebastián D, Imbernón M, Castaño C, Garcia A, et al. Mitofusin 2 in POMC neurons connects ER stress with leptin resistance and energy imbalance. Cell (2013) 152:172-87. doi: 10.1016/j.cell.2013.09.003

65. Ramírez S, Gómez-Valadés AG, Schneeberger M, Varela L, Haddad-Tóvolli R, Altirriba J, et al. Mitochondrial Dynamics Mediated by Mitofusin 1 Is Required for POMC Neuron Glucose-Sensing and Insulin Release Control. Cell Metab (2017) 25:1390-9. doi: 10.1016/j.cmet.2017.05.010

66. Ishihara N, Eura Y, Mihara K. Mitofusin 1 and 2 play distinct roles in mitochondrial fusion reactions via GTPase activity. J Cell Sci (2014) 117 (26):6535-46. doi: 10.1242/jcs.01565

67. De Brito OM, Scorrano L. Mitofusin 2 tethers endoplasmic reticulum to mitochondria. Nature (2008) 456:605-10. doi: 10.1038/nature07534
68. Paeger L, Pippow A, Hess S, Paehler M, Klein AC, Husch A, et al. Energy imbalance alters $\mathrm{Ca} 2+$ handling and excitability of POMC neurons. Elife (2017) 6:e25641. doi: 10.7554/eLife.25641

69. Sebastián D, Hernández-Alvarez MI, Segalés J, Sorianello E, Muñoz JP, Sala $\mathrm{D}$, et al. Mitofusin 2 (Mfn2) links mitochondrial and endoplasmic reticulum function with insulin signaling and is essential for normal glucose homeostasis. Proc Natl Acad Sci USA (2012) 109:5523-8. doi: 10.1073/ pnas.1108220109

70. Filippi BM, Yang CS, Tang C, Lam TKT. Insulin Activates Erk1/2 Signaling in the Dorsal Vagal Complex to Inhibit Glucose Production. Cell Metab (2012) 16:500-10. doi: 10.1016/j.cmet.2012.09.005

71. Filippi BM, Bassiri A, Abraham MA, Duca FA, Yue JTY, Lam TKT. Insulin signals through the dorsal vagal complex to regulate energy balance. Diabetes (2014) 63:892-9. doi: 10.2337/db13-1044

72. Filippi BM, Abraham MA, Silva PN, Rasti M, LaPierre MP, Bauer PV, et al. Dynamin-Related Protein 1-Dependent Mitochondrial Fission Changes in the Dorsal Vagal Complex Regulate Insulin Action. Cell Rep (2017) 18:23019. doi: 10.1016/j.celrep.2017.02.035

73. Ono H, Pocai A, Wang Y, Sakoda H, Asano T, Backer JM, et al. Activation of hypothalamic S6 kinase mediates diet-induced hepatic insulin resistance in rats. J Clin Invest (2008) 118:2959-68. doi: 10.1172/JCI34277

74. Cassidy-Stone A, Chipuk JE, Ingerman E, Song C, Yoo C, Kuwana T, et al. Chemical Inhibition of the Mitochondrial Division Dynamin Reveals Its Role in Bax/Bak-Dependent Mitochondrial Outer Membrane Permeabilization. Dev Cell (2008) 14:193-204. doi: 10.1016/j.devcel. 2007.11.019

75. Figueroa-Romero C, Iñiguez-Lluhí JA, Stadler J, Chang C-R, Arnoult D, Keller PJ, et al. SUMOylation of the mitochondrial fission protein Drpl occurs at multiple nonconsensus sites within the B domain and is linked to its activity cycle. FASEB J (2009) 23:3917-27. doi: 10.1096/fj.09-136630

76. Chang CR, Blackstone C. Cyclic AMP-dependent protein kinase phosphorylation of Drp1 regulates its GTPase activity and mitochondrial morphology. J Biol Chem (2007) 282:21583-7. doi: 10.1074/jbc.C700083200

77. Thaler JP, Yi CX, Schur EA, Guyenet SJ, Hwang BH, Dietrich MO, et al. Obesity is associated with hypothalamic injury in rodents and humans. J Clin Invest (2012) 122:153-62. doi: 10.1172/JCI59660

78. Bélanger M, Allaman I, Magistretti PJ. Brain energy metabolism: Focus on Astrocyte-neuron metabolic cooperation. Cell Metab (2011) 14:724-38. doi: 10.1016/j.cmet.2011.08.016

79. Hertz L, Peng L, Dienel GA. Energy metabolism in astrocytes: High rate of oxidative metabolism and spatiotemporal dependence on glycolysis/ glycogenolysis. J Cereb Blood Flow Metab (2007) 27:219-49. doi: 10.1038/ sj.jcbfm. 9600343

80. Supplie LM, Düking T, Campbell G, Diaz F, Moraes CT, Götz M, et al. RespirationDeficient Astrocytes Survive As Glycolytic Cells In Vivo. J Neurosci (2017) 37:423142. doi: 10.1523/JNEUROSCI.0756-16.2017

81. Lovatt D, Sonnewald U, Waagepetersen HS, Schousboe A, He W, Lin JHC, et al. The transcriptome and metabolic gene signature of protoplasmic astrocytes in the adult murine cortex. J Neurosci (2007) 27:12255-66. doi: 10.1523/JNEUROSCI.3404-07.2007

82. Motori E, Puyal J, Toni N, Ghanem A, Angeloni C, Malaguti M, et al. Inflammation-induced alteration of astrocyte mitochondrial dynamics requires autophagy for mitochondrial network maintenance. Cell Metab (2013) 18:844-59. doi: 10.1016/j.cmet.2013.11.005

83. Balland E, Cowley MA. Short-term high-fat diet increases the presence of astrocytes in the hypothalamus of C57BL6 mice without altering leptin sensitivity. J Neuroendocrinol (2017) 29. doi: 10.1111/jne.12504

84. Buckman LB, Thompson MM, Lippert RN, Blackwell TS, Yull FE, Ellacott KLJ. Evidence for a novel functional role of astrocytes in the acute homeostatic response to high-fat diet intake in mice. Mol Metab (2015) 4:58-63. doi: 10.1016/j.molmet.2014.10.001

85. Garfield AS, Shah BP, Madara JC, Burke LK, Patterson CM, Flak J, et al. A parabrachial-hypothalamic cholecystokinin neurocircuit controls counterregulatory responses to hypoglycemia. Cell Metab (2014) 20:10307. doi: $10.1016 /$ j.cmet.2014.11.006

86. Roman CW, Derkach VA, Palmiter RD. Genetically and functionally defined NTS to PBN brain circuits mediating anorexia. Nat Commun (2016) 7:11905. doi: $10.1038 /$ ncomms11905 
87. Flak JN, Patterson CM, Garfield AS, D’Agostino G, Goforth PB, Sutton AK, et al. Leptin-inhibited PBN neurons enhance responses to hypoglycemia in negative energy balance. Nat Neurosci (2014) 17:1744-50. doi: 10.1038/ nn.3861

88. Göbel J, Engelhardt E, Pelzer P, Sakthivelu V, Jahn HM, Jevtic M, et al. Mitochondria-Endoplasmic Reticulum Contacts in Reactive Astrocytes Promote Vascular Remodeling. Cell Metab (2020) 31:791-808.e8. doi: 10.1016/j.cmet.2020.03.005

89. Horvath TL, Sarman B, García-Cáceres C, Enriori PJ, Sotonyi P, Shanabrough M, et al. Synaptic input organization of the melanocortin system predicts diet-induced hypothalamic reactive gliosis and obesity. Proc Natl Acad Sci USA (2010) 107:14875-80. doi: 10.1073/pnas.1004282107

90. Barreto-Vianna ARC, Aguila MB, Mandarim-De-Lacerda CA. Effects of liraglutide in hypothalamic arcuate nucleus of obese mice. Obesity (2016) 24:626-33. doi: 10.1002/oby.21387

91. Naznin F, Sakoda H, Okada T, Tsubouchi H, Waise TMZ, Arakawa K, et al. Canagliflozin, a sodium glucose cotransporter 2 inhibitor, attenuates obesity-induced inflammation in the nodose ganglion, hypothalamus, and skeletal muscle of mice. Eur J Pharmacol (2017) 794:37-44. doi: 10.1016/ j.ejphar.2016.11.028

92. Nègre-Salvayre A, Hirtz C, Carrera G, Cazenave R, Troly M, Salvayre R, et al. A role for uncoupling protein-2 as a regulator of mitochondrial hydrogen peroxide generation. FASEB J (1997) 11:809-15. doi: 10.1096/fasebj.11.10.9271366

93. Arsenijevic D, Onuma H, Pecqueur C, Raimbault S, Manning BS, Miroux B, et al. Disruption of the uncoupling protein-2 gene in mice reveals a role in immunity and reactive oxygen species production. Nat Genet (2000) 26:4359. doi: $10.1038 / 82565$

94. Arsenijevic D, Clavel S, Sanchis D, Plamondon J, Huang Q, Ricquier D, et al. Induction of Ucp2 expression in brain phagocytes and neurons following murine toxoplasmosis: An essential role of IFN- $\gamma$ and an association with negative energy balance. J Neuroimmunol (2007) 186:121-32. doi: 10.1016/ j.jneuroim.2007.03.013

95. Dienel GA. Fueling and imaging brain activation. ASN Neuro (2012) 4(5): e00093. doi: 10.1042/AN20120021

96. Koepsell H. Glucose transporters in brain in health and disease. Pflugers Arch Eur J Physiol (2020) 472:1299-1343. doi: 10.1007/s00424-020-02441-x

97. Navale AM, Paranjape AN. Glucose transporters: physiological and pathological roles. Biophys Rev (2016) 8(1):5-9. doi: 10.1007/s12551-0150186-2

98. Dick APK, Harik SI, Klip A, Walker DM. Identification and characterization of the glucose transporter of the blood-brain barrier by cytochalasin B binding and immunological reactivity. Proc Natl Acad Sci USA (1984) 81:7233-7. doi: 10.1073/pnas.81.22.7233

99. Simpson IA, Carruthers A, Vannucci SJ. Supply and demand in cerebral energy metabolism: The role of nutrient transporters. J Cereb Blood Flow Metab (2007) 27:1766-91. doi: 10.1038/sj.jcbfm.9600521

100. Morgello S, Uson RR, Schwartz EJ, Haber RS. The human blood-brain barrier glucose transporter (GLUT1) is a glucose transporter of gray matter astrocytes. Glia (1995) 14:43-54. doi: 10.1002/glia.440140107

101. Leino RL, Gerhart DZ, Van Bueren AM, McCall AL, Drewes LR. Ultrastructural localization of GLUT 1 and GLUT 3 glucose transporters in rat brain. J Neurosci Res (1997) 49:617-26. doi: 10.1002/(SICI)1097-4547 (19970901)49:5<617::AID-JNR12>3.0.CO;2-S

102. Yu AS, Hirayama BA, Timbol G, Liu J, Basarah E, Kepe V, et al. Functional expression of SGLTs in rat brain. Am J Physiol - Cell Physiol (2010) 299: C1277-84. doi: 10.1152/ajpcell.00296.2010

103. Yu AS, Hirayama BA, Timbol G, Liu J, Diez-Sampedro A, Kepe V, et al. Regional distribution of SGLT activity in rat brain in vivo. Am J Physiol - Cell Physiol (2013) 304:C240-47. doi: 10.1152/ajpcell.00317.2012

104. O’Malley D, Reimann F, Simpson AK, Gribble FM. Sodium-coupled glucose cotransporters contribute to hypothalamic glucose sensing. Diabetes (2006) 55:3381-6. doi: 10.2337/db06-0531

105. Pozo M, Claret M. Hypothalamic Control of Systemic Glucose Homeostasis: The Pancreas Connection. Trends Endocrinol Metab (2018) 29:581-94. doi: 10.1016/j.tem.2018.05.001

106. Jin S, Diano S. Mitochondrial dynamics and hypothalamic regulation of metabolism. Endocrinology (2018) 159:3596-604. doi: 10.1210/en.201800667
107. Routh VH, Hao L, Santiago AM, Sheng Z, Zhou C. Hypothalamic glucose sensing: Making ends meet. Front Syst Neurosci (2014). doi: 10.3389/ fnsys. 2014.00236

108. Lam TKT, Gutierrez-Juarez R, Pocai A, Rossetti L. Medicine: Regulation of blood glucose by hypothalamic pyruvate metabolism. Science (80- ) (2005). doi: $10.1126 /$ science. 1112085

109. Fioramonti X, Chrétien C, Leloup C, Pénicaud L. Recent advances in the cellular and molecular mechanisms of hypothalamic neuronal glucose detection. Front Physiol (2017) 8. doi: 10.3389/fphys.2017.00875

110. Wang R, Liu X, Hentges ST, Dunn-Meynell AA, Levin BE, Wang W, et al. The regulation of glucose-excited neurons in the hypothalamic arcuate nucleus by glucose and feeding-relevant peptides. Diabetes (2004). doi: 10.2337/diabetes.53.8.1959

111. Nichols CG. KATP channels as molecular sensors of cellular metabolism. Nature (2006). doi: 10.1038/nature04711

112. Hibino H, Inanobe A, Furutani K, Murakami S, Findlay I, Kurachi Y. Inwardly rectifying potassium channels: Their structure, function, and physiological roles. Physiol Rev (2010). doi: 10.1152/physrev.00021.2009

113. Leloup C, Orosco M, Serradas P, Nicolädis S, Pénicaud L. Specific inhibition of GLUT2 in arcuate nucleus by antisense oligonucleotides suppresses nervous control of insulin secretion. Mol Brain Res (1998) 57:275-80. doi: 10.1016/S0169-328X(98)00097-7

114. Wan HZ, Hulsey MG, Martin RJ. Intracerebroventricular administration of antisense oligodeoxynucleotide against GLUT2 glucose transporter mRNA reduces food intake, body weight change and glucoprivic feeding response in rats. J Nutr (1998) 128:287-91. doi: 10.1093/jn/128.2.287

115. Bady I, Marty N, Dallaporta M, Emery M, Gyger J, Tarussio D, et al. Evidence from glut2-null mice that glucose is a critical physiological regulator of feeding. Diabetes (2006) 55:988-95. doi: 10.2337/ diabetes.55.04.06.db05-1386

116. Stolarczyk E, Guissard C, Michau A, Even PC, Grosfeld A, Serradas P, et al. Detection of extracellular glucose by GLUT2 contributes to hypothalamic control of food intake. Am J Physiol - Endocrinol Metab (2010) 298:E1078-87. doi: 10.1152/ajpendo.00737.2009

117. Stolarczyk E, Le Gall M, Even P, Houllier A, Serradas P, Brot-Laroche E, et al. Loss of sugar detection by GLUT2 affects glucose homeostasis in mice. PloS One (2007) 2:e1288. doi: 10.1371/journal.pone.0001288

118. Kang L, Routh VH, Kuzhikandathil EV, Gaspers LD, Levin BE. Physiological and Molecular Characteristics of Rat Hypothalamic Ventromedial Nucleus Glucosensing Neurons. Diabetes (2004) 53:549-59. doi: 10.2337/diabetes.53.3.549

119. Reno CM, Puente EC, Sheng Z, Daphna-Iken D, Bree AJ, Routh VH, et al. Brain GLUT4 knockout mice have impaired glucose tolerance, decreased insulin sensitivity, and impaired hypoglycemic counterregulation. Diabetes (2017) 66:587-97. doi: 10.2337/db16-0917

120. Fan X, Chan O, Ding Y, Zhu W, Mastaitis J, Sherwin R. Reduction in SGLT1 mRNA expression in the ventromedial hypothalamus improves the counterregulatory responses to hypoglycemia in recurrently hypoglycemic and diabetic rats. Diabetes (2015) 64:3564-72. doi: 10.2337/db15-0022

121. Chari M, Yang CS, Lam CKL, Lee K, Mighiu P, Kokorovic A, et al. Glucose transporter-1 in the hypothalamic glial cells mediates glucose sensing to regulate glucose production in vivo. Diabetes (2011) 60:1901-6. doi: 10.2337/ db11-0120

122. Kim JG, Suyama S, Koch M, Jin S, Argente-Arizon P, Argente J, et al. Leptin signaling in astrocytes regulates hypothalamic neuronal circuits and feeding. Nat Neurosci (2014) 17:908-10. doi: 10.1038/nn.3725

123. Chowen JA, Fonseca FRD, Alvarez E, Navarro M, García-Segura LM, Blázquez E. Increased glucagon-like peptide-1 receptor expression in glia after mechanical lesion of the rat brain. Neuropeptides (1999) 33:212-15. doi: 10.1054/npep. 1999.0757

124. Iwai T, Ito S, Tanimitsu K, Udagawa S, Oka JI. Glucagon-like peptide-1 inhibits LPS-induced IL-1 $\beta$ production in cultured rat astrocytes. Neurosci Res (2006) 55:352-60. doi: 10.1016/j.neures.2006.04.008

125. Kobayashi K, Iwai T, Sasaki-Hamada S, Kamanaka G, Oka JI. Exendin (539), an antagonist of GLP-1 receptor, modulates synaptic transmission via glutamate uptake in the dentate gyrus. Brain Res (2013) 1505:1-10. doi: 10.1016/j.brainres.2013.01.012

126. Timper K, Del Río-Martín A, Cremer AL, Bremser S, Alber J, Giavalisco P, et al. GLP-1 Receptor Signaling in Astrocytes Regulates Fatty Acid 
Oxidation, Mitochondrial Integrity, and Function. Cell Metab (2020) 31:1189-1205. doi: 10.1016/j.cmet.2020.05.001

127. Üner AG, Keçik O, Quaresma PGF, De Araujo TM, Lee H, Li W, et al. Role of POMC and AgRP neuronal activities on glycaemia in mice. Sci Rep (2019) 9:13068. doi: 10.1038/s41598-019-49295-7

128. Ibrahim N, Bosch MA, Smart JL, Qiu J, Rubinstein M, Rønnekleiv OK, et al. Hypothalamic proopiomelanocortin neurons are glucose responsive and express KATP channels. Endocrinology (2003) 144:1331-40. doi: 10.1210/ en.2002-221033

129. Parton LE, Ye CP, Coppari R, Enriori PJ, Choi B, Zhang CY, et al. Glucose sensing by POMC neurons regulates glucose homeostasis and is impaired in obesity. Nature (2007) 449:228-32. doi: 10.1038/nature06098

130. Hu J, Jiang L, Low MJ, Rui L. Glucose rapidly induces different forms of excitatory synaptic plasticity in hypothalamic POMC neurons. PloS One (2014) 9:e105080. doi: 10.1371/journal.pone.0105080

131. Nuzzaci D, Cansell C, Liénard F, Nédélec E, Ben Fradj S, Castel J, et al. Postprandial Hyperglycemia Stimulates Neuroglial Plasticity in Hypothalamic POMC Neurons after a Balanced Meal. Cell Rep (2020) 30:3067-78. doi: 10.1016/j.celrep.2020.02.029

132. Jo YH, Su Y, Gutierrez-Juarez R, Chua S. Oleic acid directly regulates POMC neuron excitability in the hypothalamus. J Neurophysiol (2009) 101:2305-16. doi: 10.1152/jn.91294.2008

133. Zhang CY, Baffy G, Perret P, Krauss S, Peroni O, Grujic D, et al. Uncoupling protein-2 negatively regulates insulin secretion and is a major link between obesity, $\beta$ cell dysfunction, and type 2 diabetes. Cell (2001) 105:745-55. doi: 10.1016/S0092-8674(01)00378-6

134. Welcome MO, Mastorakis NE. Emerging Concepts in Brain Glucose Metabolic Functions: From Glucose Sensing to How the Sweet Taste of Glucose Regulates Its Own Metabolism in Astrocytes and Neurons. NeuroMol Med (2018) 20:281-300. doi: 10.1007/s12017-018-8503-0

135. Baltzer C, Tiefenböck SK, Frei C. Mitochondria in response to nutrients and nutrient-sensitive pathways. Mitochondrion (2010) 10:589-97. doi: 10.1016/ j.mito.2010.07.009

136. Mandl J, Mészáros T, Bánhegyi G, Hunyady L, Csala M. Endoplasmic reticulum: nutrient sensor in physiology and pathology. Trends Endocrinol Metab (2009) 20:194-201. doi: 10.1016/j.tem.2009.01.003

137. Diano S, Liu ZW, Jeong JK, Dietrich MO, Ruan HB, Kim E, et al. Peroxisome proliferation-associated control of reactive oxygen species sets melanocortin tone and feeding in diet-induced obesity. Nat Med (2011) 17:1121-7. doi: $10.1038 / \mathrm{nm} .2421$

138. Murphy MP. How mitochondria produce reactive oxygen species. Biochem J (2009) 417:1-13. doi: 10.1042/BJ20081386

139. Leloup C, Magnan C, Benani A, Bonnet E, Alquier T, Offer G, et al. Mitochondrial reactive oxygen species are required for hypothalamic glucose sensing. Diabetes (2006) 55:2084-90. doi: 10.2337/db06-0086

140. Andrews ZB, Liu ZW, Wallingford N, Erion DM, Borok E, Friedman JM, et al. UCP2 mediates ghrelin's action on NPY/AgRP neurons by lowering free radicals. Nature (2008) 454:846-51. doi: 10.1038/nature07181

141. Yoon Y, Galloway CA, Jhun BS, Yu T. Mitochondrial dynamics in diabetes. Antioxid Redox Signal (2011) 14:439-57. doi: 10.1089/ars.2010.3286

142. Chang GQ, Karatayev O, Davydova Z, Wortley K, Leibowitz SF. Glucose injection reduces neuropeptide $\mathrm{Y}$ and agouti-related protein expression in the arcuate nucleus: A possible physiological role in eating behavior. Mol Brain Res (2005) 135:69-80. doi: 10.1016/j.molbrainres.2004. 12.017

143. Clark JT, Kalra PS, Crowley WR, Kalra SP. Neuropeptide $\gamma$ and human pancreatic polypeptide stimulate feeding behavior in rats. Endocrinology (1984) 115:427-9. doi: 10.1210/endo-115-1-427

144. Stanley BG, Leibowitz SF. Neuropeptide Y injected in the paraventricular hypothalamus: A powerful stimulant of feeding behavior. Proc Natl Acad Sci USA (1985) 82:3940-3. doi: 10.1073/pnas.82.11.3940

145. Bagnol D, Lu XY, Kaelin CB, Day HE, Ollmann M, Gantz I, et al. Anatomy of an endogenous antagonist: relationship between Agouti-related protein and proopiomelanocortin in brain. J Neurosci (1999) 19:RC26. doi: 10.1523/ jneurosci.19-18-j0004.1999

146. Fioramonti X, Contie S, Song Z, Routh VH, Lorsignol A, Pénicaud L. Characterization of Glucosensing Neuron Subpopulations in the Arcuate Nucleus. Diabetes (2007) 56:1219-27. doi: 10.2337/db06-0567.ARC
147. Murphy BA, Fioramonti X, Jochnowitz N, Fakira K, Gagen K, Contie S, et al. Fasting enhances the response of arcuate neuropeptide Y-glucose-inhibited neurons to decreased extracellular glucose. Am J Physiol - Cell Physiol (2009) 296:C746-56. doi: 10.1152/ajpcell.00641.2008

148. Krashes MJ, Koda S, Ye CP, Rogan SC, Adams AC, Cusher DS, et al. Rapid, reversible activation of AgRP neurons drives feeding behavior in mice. J Clin Invest (2011) 121:1424-8. doi: 10.1172/JCI46229

149. Aponte Y, Atasoy D, Sternson SM. AGRP neurons are sufficient to orchestrate feeding behavior rapidly and without training. Nat Neurosci (2011) 14:351-5. doi: 10.1038/nn.2739

150. Engström Ruud L, Pereira MMA, de Solis AJ, Fenselau H, Brüning JC. NPY mediates the rapid feeding and glucose metabolism regulatory functions of AgRP neurons. Nat Commun (2020) 11. doi: 10.1038/s41467-020-14291-3

151. Kurita H, Xu KY, Maejima Y, Nakata M, Dezaki K, Santoso P, et al. Arcuate $\mathrm{Na}+\mathrm{K}+$-ATPase senses systemic energy states and regulates feeding behavior through glucose-inhibited neurons. Am J Physiol - Endocrinol Metab (2015) 309:E320-33. doi: 10.1152/ajpendo.00446.2014

152. Mountjoy PD, Rutter GA. Glucose sensing by hypothalamic neurones and pancreatic islet cells: AMPle evidence for common mechanisms? Exp Physiol (2007) 92:311-9. doi: 10.1113/expphysiol.2006.036004

153. Claret M, Smith MA, Batterham RL, Selman C, Choudhury AI, Fryer LGD, et al. AMPK is essential for energy homeostasis regulation and glucose sensing by POMC and AgRP neurons. J Clin Invest (2007) 117:2325-36. doi: 10.1172/JCI31516

154. Dodd GT, Lee-Young RS, Brüning JC, Tiganis T. TCPTP regulates insulin signaling in AgRP neurons to coordinate glucose metabolism with feeding. Diabetes (2018) 67:1246-57. doi: 10.2337/db17-1485

155. Liu T, Kong D, Shah BP, Ye C, Koda S, Saunders A, et al. Fasting activation of AgRP neurons requires NMDA receptors and involves spinogenesis and increased excitatory tone. Neuron (2012) 73:511-22. doi: 10.1016/j.neuron.2011.11.027

156. Yang Y, Atasoy D, Su HH, Sternson SM. Hunger states switch a flip-flop memory circuit via a synaptic AMPK-dependent positive feedback loop. Cell (2011) 146:992-1003. doi: 10.1016/j.cell.2011.07.039

157. Coppola A, Liu ZW, Andrews ZB, Paradis E, Roy MC, Friedman JM, et al. A Central Thermogenic-like Mechanism in Feeding Regulation: An Interplay between Arcuate Nucleus T3 and UCP2. Cell Metab (2007) 5:21-33. doi: 10.1016/j.cmet.2006.12.002

158. Newton AJ, Hess S, Paeger L, Vogt MC, Lascano JF, Nillni EA, et al. AgRP innervation onto POMC neurons increases with age and is accelerated with chronic high-fat feeding in male mice. Endocrinology (2013) 154:172-83. doi: 10.1210/en.2012-1643

159. Kang L, Dunn-Meynell AA, Routh VH, Gaspers LD, Nagata Y, Nishimura T, et al. Glucokinase is a critical regulator of ventromedial hypothalamic neuronal glucosensing. Diabetes (2006) 55:412-20. doi: 10.2337/diabetes.55.02.06.db051229

160. Chan O, Zhu W, Ding Y, McCrimmon RJ, Sherwin RS. Blockade of GABAA receptors in the ventromedial hypothalamus further stimulates glucagon and sympathoadrenal but not the hypothalamo- pituitary-adrenal response to hypoglycemia. Diabetes (2006) 55:1080-7. doi: 10.2337/diabetes. 55.04.06.db05-0958

161. Carneiro L, Allard C, Guissard C, Fioramonti X, Tourrel-Cuzin C, Bailbé D, et al. Importance of Mitochondrial Dynamin-Related Protein 1 in Hypothalamic Glucose Sensitivity in Rats. Antioxid Redox Signal (2012) 17:433-44. doi: 10.1089/ars.2011.4254

162. Toda C, Kim JD, Impellizzeri D, Cuzzocrea S, Liu ZW, Diano S. UCP2 Regulates Mitochondrial Fission and Ventromedial Nucleus Control of Glucose Responsiveness. Cell (2016) 164:872-83. doi: 10.1016/j.cell.2016.02.010

163. Desmoulins L, Chrétien C, Paccoud R, Collins S, Cruciani-Guglielmacci C, Galinier A, et al. Mitochondrial Dynamin-Related Protein 1 (DRP1) translocation in response to cerebral glucose is impaired in a rat model of early alteration in hypothalamic glucose sensing. Mol Metab (2019) 20:16677. doi: 10.1016/j.molmet.2018.11.007

164. Diano S, Horvath TL. Mitochondrial uncoupling protein 2 (UCP2) in glucose and lipid metabolism. Trends Mol Med (2012) 18:52-8. doi: 10.1016/j.molmed.2011.08.003

165. Abraham MA, Filippi BM, Kang GM, Kim MS, Lam TKT. Insulin action in the hypothalamus and dorsal vagal complex. Exp Physiol (2014) 99:1104-9. doi: 10.1113/expphysiol.2014.079962 
166. Adachi A, Kobashi M, Funahashi M. Glucose-Responsive Neurons In the Brainstem. Obes Res (1995) 3:735S-40S. doi: 10.1002/j.1550-8528.1995.tb00493.x

167. Pocai A, Obici S, Schwartz GJ, Rossetti L. A brain-liver circuit regulates glucose homeostasis. Cell Metab (2005) 1:53-61. doi: 10.1016/j.cmet. 2004.11.001

168. Willing AE, Berthoud HR. Gastric distension-induced c-fos expression in catecholaminergic neurons of rat dorsal vagal complex. Am J Physiol - Regul Integr Comp Physiol (1997) 272:R59-67. doi: 10.1152/ajpregu.1997.272.1.r59

169. Williams EKK, Chang RBB, Strochlic DEE, Umans BDD, Lowell BBB, Liberles SDD. Sensory Neurons that Detect Stretch and Nutrients in the Digestive System. Cell (2016) 166:209-21. doi: 10.1016/j.cell.2016.05.011

170. Gross PM, Wainman DS, Shaver SW, Wall KM, Ferguson AV. Metabolic activation of efferent pathways from the rat area postrema. Am J Physiol Regul Integr Comp Physiol (1990) 258:R788-97. doi: 10.1152/ajpregu. 1990.258.3.r788

171. Mizuno Y, Oomura Y. Glucose responding neurons in the nucleus tractus solitarius of the rat: In vitro study. Brain Res (1984) 307:109-16. doi: 10.1016/0006-8993(84)90466-9

172. De Bernardis Murat C, Leão RM. A voltage-dependent depolarization induced by low external glucose in neurons of the nucleus of the tractus solitarius: interaction with KATP channels. J Physiol (2019) 597:2515-32. doi: $10.1113 /$ JP277729

173. Mimee A, Ferguson AV. Glycemic state regulates melanocortin, but not nesfatin-1, responsiveness of glucose-sensing neurons in the nucleus of the solitary tract. Am J Physiol - Regul Integr Comp Physiol (2015) 308:R690-9. doi: 10.1152/ajpregu.00477.2014

174. Lamy CM, Sanno H, Labouèbe G, Picard A, Magnan C, Chatton JY, et al. Hypoglycemia-activated GLUT2 neurons of the nucleus tractus solitarius stimulate vagal activity and glucagon secretion. Cell Metab (2014) 19:527-38. doi: 10.1016/j.cmet.2014.02.003

175. Balfour RH, Hansen AMK, Trapp S. Neuronal responses to transient hypoglycaemia in the dorsal vagal complex of the rat brainstem. J Physiol (2006) 570:469-84. doi: 10.1113/jphysiol.2005.098822

176. Balfour RH, Trapp S. Ionic currents underlying the response of rat dorsal vagal neurones to hypoglycaemia and chemical anoxia. J Physiol (2007) 579:691-702. doi: 10.1113/jphysiol.2006.126094

177. Boychuk CR, Gyarmati P, Xu H, Smith BN. Glucose sensing by GABaergic neurons in the mouse nucleus tractus solitarii. J Neurophysiol (2015) 114:999-1007. doi: 10.1152/jn.00310.2015

178. Boychuk CR, Smith KC, Peterson LE, Boychuk JA, Butler CR, Derera ID, et al. A hindbrain inhibitory microcircuit mediates vagally-coordinated glucose regulation. Sci Rep (2019) 9:2722. doi: 10.1038/s41598-01939490-x

179. Roberts BL, Zhu M, Zhao H, Dillon C, Appleyard SM. High glucose increases action potential firing of catecholamine neurons in the nucleus of the solitary tract by increasing spontaneous glutamate inputs. Am J Physiol - Regul Integr Comp Physiol (2017) 313:R229-39. doi: 10.1152/ ajpregu.00413.2016

180. Aklan I, Sayar Atasoy N, Yavuz Y, Ates T, Coban I, Koksalar F, et al. NTS Catecholamine Neurons Mediate Hypoglycemic Hunger via Medial Hypothalamic Feeding Pathways. Cell Metab (2020) 31:313-26. doi: 10.1016/j.cmet.2019.11.016

181. Zhan C, Zhou J, Feng Q, Zhang JE, Lin S, Bao J, et al. Acute and long-term suppression of feeding behavior by POMC neurons in the brainstem and hypothalamus, respectively. J Neurosci (2013) 33:3624-32. doi: 10.1523/ JNEUROSCI.2742-12.2013
182. Guan HZ, Dong J, Jiang ZY, Chen X. MSH influences the excitability of feeding-related neurons in the hypothalamus and dorsal vagal complex of rats. BioMed Res Int (2017) 2017. doi: 10.1155/2017/2034691

183. McDougal DH, Viard E, Hermann GE, Rogers RC. Astrocytes in the hindbrain detect glucoprivation and regulate gastric motility. Auton Neurosci Basic Clin (2013) 175:61-9. doi: 10.1016/j.autneu.2012.12.006

184. Rogers RC, Burke SJ, Collier JJ, Ritter S, Hermann GE. Evidence that hindbrain astrocytes in the rat detect low glucose with a glucose transporter 2-phospholipase C-calcium release mechanism. Am J Physiol Regul Integr Comp Physiol (2020) 318:R38-48. doi: 10.1152/AJPREGU .00133 .2019

185. Perez Ortiz JM, Swerdlow RH. Mitochondrial dysfunction in Alzheimer's disease: Role in pathogenesis and novel therapeutic opportunities. $\mathrm{Br} J$ Pharmacol (2019) 176:3489-507. doi: 10.1111/bph.14585

186. Chen C, Turnbull DM, Reeve AK. Mitochondrial dysfunction in Parkinson's disease-cause or consequence? Biol (Basel) (2019) 8:38. doi: 10.3390/ biology 8020038

187. Carmo C, Naia L, Lopes C, Rego AC. Mitochondrial dysfunction in huntington's disease. Adv Exp Med Biol (2018) 59-83. doi: 10.1007/978-3319-71779-1_3

188. Smith EF, Shaw PJ, De Vos KJ. The role of mitochondria in amyotrophic lateral sclerosis. Neurosci Lett (2019) 710:132933. doi: 10.1016/j.neulet. 2017.06.052

189. Anstey KJ, Cherbuin N, Budge M, Young J. Body mass index in midlife and late-life as a risk factor for dementia: A meta-analysis of prospective studies. Obes Rev (2011) 12:e426-37. doi: 10.1111/j.1467-789X.2010.00825.x

190. Cukierman T, Gerstein HC, Williamson JD. Cognitive decline and dementia in diabetes - Systematic overview of prospective observational studies. Diabetologia (2005) 48:2460-9. doi: 10.1007/s00125-005-0023-4

191. Jahani-Asl A, Pilon-Larose K, Xu W, MacLaurin JG, Park DS, McBride HM, et al. The mitochondrial inner membrane GTPase, optic atrophy 1 (Opa1), restores mitochondrial morphology and promotes neuronal survival following excitotoxicity. J Biol Chem (2011) 286:4772-82. doi: 10.1074/ jbc.M110.167155

192. Oettinghaus B, Schulz JM, Restelli LM, Licci M, Savoia C, Schmidt A, et al. Synaptic dysfunction, memory deficits and hippocampal atrophy due to ablation of mitochondrial fission in adult forebrain neurons. Cell Death Differ (2016) 23:18-28. doi: 10.1038/cdd.2015.39

193. Hayakawa K, Esposito E, Wang X, Terasaki Y, Liu Y, Xing C, et al. Transfer of mitochondria from astrocytes to neurons after stroke. Nature (2016) 535:551-5. doi: 10.1038/nature18928

194. Xue A, Wu Y, Zhu Z, Zhang F, Kemper KE, Zheng Z, et al. Genome-wide association analyses identify 143 risk variants and putative regulatory mechanisms for type 2 diabetes. Nat Commun (2018) 9:1-14. doi: 10.1038/ s41467-018-04951-w

Conflict of Interest: The authors declare that the research was conducted in the absence of any commercial or financial relationships that could be construed as a potential conflict of interest.

Copyright (c) 2020 Haigh, New and Filippi. This is an open-access article distributed under the terms of the Creative Commons Attribution License (CC BY). The use, distribution or reproduction in other forums is permitted, provided the original author(s) and the copyright owner(s) are credited and that the original publication in this journal is cited, in accordance with accepted academic practice. No use, distribution or reproduction is permitted which does not comply with these terms. 